Revista de Estudios Histórico-Jurídicos

[Sección derecho romano]

XL (Valparaíso, Chile, 2018)

[pp. $71-95]$

\title{
LA IMPROBABLE EXISTENCIA DE IMPENSAE EN LA LEX ICILIA DE AVENTINO PUBLICANDO
}

[The unlikely existence of impensae in the Lex Icilia de Aventino publicando]

\author{
Carolina Schiele Manzor* \\ Universidad Central de Chile
}

\section{RESUMEN}

Se ha sostenido que la doctrina de las impensae, propia de la dote, se extendió a otras esferas del Derecho privado, en especial a la reivindicatio. En esta sedes su estudio se centra en el periodo clásico, sin mayor preocupación por la época anterior. El propósito de este trabajo es la búsqueda de precedentes del tratamiento clásico del reembolso de las impensae, a través de la revisión de la legislación regia y republicana sobre repartición y distribución de tierras. Especial atención merece la Lex Icilia de Aventino publicando, puesto que en ella se consagra un pago por gastos de edificación en terrenos adquiridos por fuerza y usurpación. Sin embargo, se puede concluir, que la regulación de las tierras del

\begin{abstract}
It has been argued that the doctrine of the impensae, related to the dowry, was extended to other areas of private law, especially to the reivindicatio. On this matter its study has focused on the classical age, without bearing great concern for the previous period. The purpose of this paper is the search for precedents with respect to the classical treatment of the impensae reimbursement, by the revision of the royal and republican laws of land distribution. Special attention is paid to the Lex Icilia de Aventino publicando because it entails a payment for the expenses of edification in lands acquired by force and usurpation. However, a conclusion can be drawn in the sense that the regulation of the Aventino's
\end{abstract}

RECIBIDO el 30 de marzo y ACEPTADO el 20 de junio de 2018

* Carolina Schiele Manzor, Profesora de Derecho Romano, Universidad Central de Chile, Dirección postal: Facultad de Derecho de la Universidad Central de Chile, Lord Cochrane 417, Torre A, piso 4, Santiago, Chile. Correo electrónico: carolina.schiele@ucentral.cl. 
monte Aventino, se fundamenta en criterios de oportunidad política que en nada se relacionan con el reembolso clásico de las impensae.

Palabras Clave

Impensae - lex Icilia de Aventino publicando-edificación. lands is based on a criterion of political opportunity, that in no way is linked to the classical reimbursement of the impensae.

KEYWORDS

Impensae - lex Icilia de Aventino publicando - building.

\section{INTRODUCCIÓN}

La "doctrina de las impensas" distingue entre las impensae (gastos) necessariae, utiles y voluptuariae. Las primeras han sido generalmente definidas desde la finalidad del mantenimiento que ellas tienen respecto de la cosa, y se señala sobre ellas, que son las indispensables para la conservación de la cosa ${ }^{1}$. Las utiles, como aquellos gastos que mejoran la cosa, aumentando su rédito, incrementando su utilidad o su valor ${ }^{2}$. Finalmente, las voluptuarias son las impensas de mero em-

1 Vid., por todos, v. dote, Cannata, Carlo Augusto, Enciclopedia del Diritto (Milano, Dott. A. Giuffrè Editore, 1958), XIV, p. 5; Bonfante, Pietro, Corso di Diritto Romano, I: Diritto di famiglia (3a edición, Milano, Dott. A. Giuffrè Editore, 1963), p. 492; Biond, Biondo, Istituzioni di Diritto Romano (4a edición, Milano, Dott. A. Giuffrè Editore, 1972), p. 279; D’ors, Alvaro, Derecho Privado Romano ( $3^{a}$ edición, Pamplona, Ediciones Universidad de Navarra S. A., 1977), pp. 194-195; Treggiari, Susan, Roman Marriage: "Iusti Coniuges" from the Time of Cicero to the Time of Ulpian (Oxford, Clarendon Press, 1991), p. 354; VocI, Pasquale, Istituzioni di Diritto Romano (6a edición, Milano, Dott. A. Giuffrè Editore, 2004), p. 286; Girard, Paul-Frédéric, Manuel élémentaire de droit romain ( $8^{\mathrm{a}}$ edición, Éditions Dalloz, Paris, 2003), pp. 369-373; FAYER, Carla, La familia romana, II: Sponsalia, matrimonio, dote (Roma, L'Erma di Bretschneider, 2005), p. 710; PÉREZ, María del Pilar, El reembolso de los gastos dotales según la nueva regulación justinianea, en D’ Ippolito, Federico (coordinador), Фı $\lambda i \alpha^{\alpha}$. Scr. per Gennaro Franciosi (Napoli, Satura Editrice, 2009), III, p. 2032. En particular, Riccobono las define como "quelle che non si possono omettere, nel senso che se trascurate ne vien grave danno alla cosa, sia fondo o edificio", RicCOBONO, Salvatore, Il compenso per spese fatte da possessori su cose altrui, en BIDR. 47 (1940), p. 5; y, asimismo, ha dicho que las impensas necesarias están dirigidas a mantener la cosa en condiciones normales y adecuadas para poder satisfacer útilmente la función a la cual ha sido destinada, de modo que si fuesen omitidas se derivaría un daño al propietario, Riccobono, Salvatore, Distinzione delle impensae e la regola fructus intelliguntur deductis impensis, en $A G .58$ (1897), p. 73.

2 Vid., por todos, v. spese, GuARneri CitATI, Andrea, Nuovo Digesto Italiano (Torino, Unione Tipografico-Editrice Torinese, 1940), XII, p. 723; v. dote, CannatA, Carlo Augusto, cit. (n. 1), p. 5; v. spese, Cervenca, Giuliano, Novissimo Digesto Italiano (Torino, Unione Tipografico-Editrice Torinese, 1970), XVII, p. 1109; Biond, Biondo, cit. (n. 1), p. 279; TreggiarI, Susan, cit. (n. 1), p. 355; Girard, Paul-Frédéric, cit. (n. 1), p. 359; GonZÁlez-Palenzuela, María Teresa, Impensas útiles dotales y voluntas mulieris, en Anuario de la Facultad de Derecho 11 (1993), p. 401; González-Palenzuela, María Teresa, Las impensas en el Derecho Romano Clásico (Extremadura, Universidad de Extremadura, 1998), p. 69; FAYER, Carla, cit. (n. 1), p. 711; o, más precisamente, los "gastos realizados en la cosa de otro con los que ésta ha adquirido una utilidad que antes no tenía o ha adquirido un valor mayor y sin los cuales la cosa no hubiera sufrido una disminución de su valor o utilidad originaria”, v. impensae utiles, GuTIÉRREZ-ALviz 
bellecimiento, de lujo o de pura agregación u ornato, sin aumentar la utilidad de la cosa y sin las cuales ella no hubiera sufrido daño o disminuido su valor, como los jardines, las pinturas. Esta categoría de gastos viene determinada, entonces, negativamente: aquellos que no son ni necesarios ni útiles ${ }^{3}$.

Estas clasificaciones -y su régimen de reembolso-, se encuentran desarrolladas por los juristas clásicos a propósito de la dote. De las fuentes jurídicas de esa época, la más connotada -donde aparece su tratamiento completo y coordinado-, es el pasaje del título De verborum significatione, Paulo, 6 ad Plautium, D. 50, 16, 79 pr.:

"Impensae necessariae" sunt, quae si factae non sint, res aut peritura aut deterior futura sit. 1. "Utiles impensas" esse Fulcinius ait, quae meliorem dotem faciant, non deteriorem esse non sinant, ex quibus reditus mulieri adquiratur: sicuti arbusti pastinationem ultra quam necesse fuerat, item doctrinam puerorum. Quorum nomine onerari mulierem ignorantem vel invitam non oportet, ne cogatur fundo aut mancipiis carere. In his impensis et pistrinum et horreum insulae dotali adiectum plerumque dicemus. 2. "Voluptariae" sunt, quae speciem dumtaxat ornant, non etiam fructum augent: ut sint viridia et aquae salientes, incrustationes, loricationes, picturae.
Son "impensas necesarias", las que si no se hicieran, la cosa habría o perecido o sufrido deterioro futuro. 1. Fulcinio dice ser "impensas útiles", las que hagan mejor la dote, no las que no permitan tener deterioro; con las cuales se adquiera réditos para la mujer, como la plantación de árboles más allá de lo que fuera necesario. También la enseñanza de los niños, a cuyo título no debe gravarse a la mujer ignorante o contra su voluntad, para que no se vea desprovista del fundo, o de los esclavos. En estas impensas decimos generalmente comprendido sea el molino, sea el granero de la casa dotal. 2. Son "voluptuarias" las que sólo adornan la especie, pero no aumentan el fruto: como son los jardines, las salientes de agua, las incrustaciones, los revestimientos pintados, las pinturas.

Junto a esta cita paulina proveniente del tema de re uxoria (de la cosa dotal $)^{4}$, existen además otros dos fragmentos que contienen el tratamiento completo de la tripartición, los cuales corresponden a trabajos postclásicos en torno a la obra de Ulpiano.

El primero se encuentra en los Tituli ex corpore Ulpiani: Liber singularis regularum (Reg.) 6. De dotibu (Sobre las dotes) ${ }^{5}$; y el segundo, los Scholia Sinaitica

y Armario, Faustino, Diccionario de Derecho Romano (4 $4^{\mathrm{a}}$ edición, Madrid, Editorial Reus S. A., 1995), p. 285.

${ }^{3}$ Vid., por todos, Biondi, Biondo, cit. (n. 1), p. 279; Treggiari, Susan, cit. (n. 1), p. 356; v. impensae voluptuosae, GutiérReZ-Alviz y Armario, Faustino, cit. (n. 2), p. 285; Fayer, Carla, cit. (n. 1), p. 712.

${ }^{4}$ Cfr. Lenel, Otto, Paling (1889, reimp. Roma, Il Cigno Galileo Galilei, 2000), I, col. 1156 (n. 1127).

${ }^{5}$ Ulpiano, Reg. 6, 14-17: "Impensarum species sunt tres: aut enim necessariae dicuntur aut utiles aut voluptuosae. 15. Necessariae sunt impensae, quibus non factis dos deterior futura est, velut si quis ruinosas aedes refecerit. 16. Utiles sunt, quibus non factis quidem deterior dos non fuerit, factis autem fructuosior effecta est, veluti si vineta et oliveta fecerit. 17. Voluptuosae sunt, quibus neque omissis deterior dos fieret neque factis fructuosior effecta est: quod evenit in viridiariis et picturis similisbusque rebus", FIRA (Florentiae, apud S. A. G. Barbèra, 1968), II, p. 270. 
ad Ulpiani Libros ad Sabinum 8, 16-19; 9, 2066. A partir de ahí, habrá que esperar hasta la obra bizantina Basilicorum libri $L X$, en el título De iure dotis et donationis ante nuptias (29.1) 1197 , para encontrar, aunque brevísima, una nueva exposición de conjunto de las tres categorías de impensas.

Si bien gran parte de los autores coincide en que el esquema de las impensas

${ }^{6}$ Como se sabe, el texto es muy lagunoso y casi no permite extraer conclusiones, aparte de tener alguna relación con los textos, todos de Ulpiano, 36 ad Sabinum de D. 25, 1, 1, 3 y 25, 1, 3, 1; 5; 9, al igual que se reconstruye el párrafo 19 con D. 25, 1, 5: Kávova Yદvikóv,

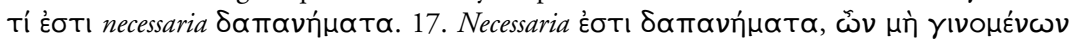

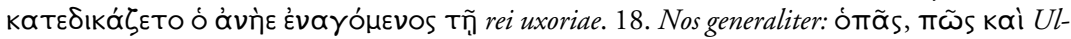

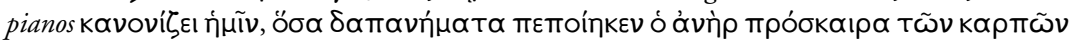

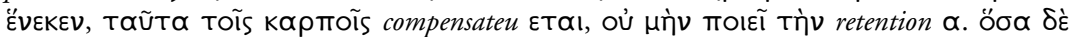

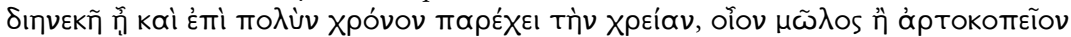

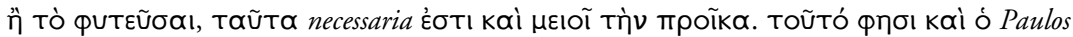

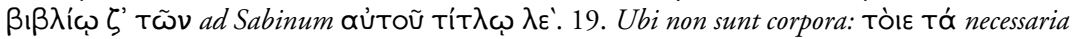

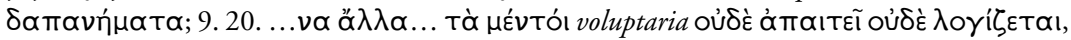

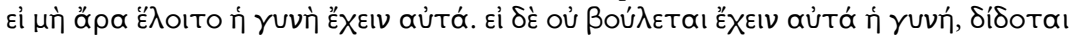

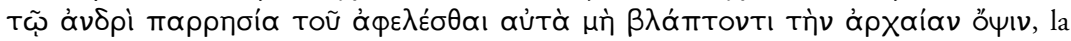
traducción latina utilizada en el resto de la investigación es la de FIRA: = "regulam generalem, quae sint necessariae impensae. 17. Necessariae impensae sunt, quibus non factis condemnaretur vir rei uxoriae actione conventus. 18. Nos generaliter: vides, quomodo etiam Ulpianus regulam nobis ponit: quas impensas pro tempore fructuum causa vir fecit, eas cum fructibus compensat nec retentionem facit: quae vero perpetuae sunt et in longum tempus utilitatem praebent, velut moles vel pistrinum vel plantatio, eae necessariae sunt et dotem minuunt. Idem ait etiam Paulus libro 7 ad Sabinum titulo 35. 19. Ubi non sunt corpora: tum necessariae impensae; 9. 20. ...voluptaria vero neque exigit neque computat nisi forte mulier eas habere praeferat. Sin autem mulier eas habere nolit, viro licentia datur eas tollere, dum priorem speciem non laedat", FIRA, cit. (n. 5), II, pp. 643 (ns. 1 y 2) y 644.

${ }^{7}$ Se trata aquí de una constitución de Justiniano contenida en Codex 5.13 (año 530), y que en la obra justinianea está bajo el título De rei uxoriae actione in ex stipulatu actionem transfusa et de natura dotibus praestita. Al llegar las Basílicas a los comentarios sobre Codex 5, 13, 1, 5 (pp. 451-452), cuyos párrafos finales son los siguientes: ....e. Sed nec ob impensas in res dotis factas retentio satis esse nobis videtur idonea. Cum enim necessariae quidem expensae dotis minuunt quantitates, utiles autem expensae non aliter in rei uxoriae actione detinebantur, nisi ex voluntate mulieris, non ab re est, si quidem voluntas mulieris intercedat, mandati actionem a nostra auctoritate marito contra uxorem indulgeri, quatenus possit per hanc hoc quod utiliter impensum est observari: vel si non intercedat mulieris voluntas, utiliter tamen res gesta est, negotiorum gestorum adversus eam sufficit actio. f. Quod si voluptariae sunt, licet voluntate eius expensae, deductio operis quod fecit, sine laesione tamen prioris speciei, marito relinquatur, ut sit omnium retentionum expeditus tractatus et ex stipulatu actio merito secundum sui naturam nullam accipiat retentionem. Lo señalado por las Basílicas (según la traducción del griego al latin de Heimbach), es lo siguiente: Cesset etiam dotis retentio ob liberos: neque enim liberos ex dote ali oportet, sed a parentibus suis. Neque enim quaerant mariti causas proferre adversos uxores ad partem dotis propter liberos retinendam, cum, si causam mulier dederit, tota dote careat. Sed neque ob impensas retentio amplius sit. Nam si quidem necessariae sunt, ipso iure dos minuitur: si vero eae, quae dotem meliorem reddunt, si quidem voluntate mulieris erogatae sunt, mandatum est: sin autem citra eius voluntatem, si quidem utiliter, est negotiorum gestorum actio. Sin autem voluptuariae sunt, sive utiliter, sive voluntate eius erogatae sint, maritus tollit tantum, quae adiecta sunt, non laedenda tamen priore rei specie. Cfr. Bas. (Lipsiae, Sumptibus Joh. Ambrosii Barth., 1843), III, pp. 449-459. 
es propio de la dote, un buen número sostiene que tuvo aplicación general y se extendió a otras esferas del derecho privado, en especial, a la reivindicatio ${ }^{8}$.

Sin embargo, la literatura especializada en la doctrina de las impensae (gastos), se inclina por prescindir de realizar cualquier revisión de la época arcaica, puesto que se estima todavía inexistente la noción misma?.

Y si se cotejan las noticias que existen a disposición, en el marco de la (consabida) penuria de las fuentes disponibles para este período, la ausencia de testimonios relevantes en esta materia hace de ésta una opinión general razonable.

Con todo, no parece apropiado omitir totalmente el tratamiento de las impensas en la etapa arcaica, puesto que en cualquier caso ya en esta época, se puede encontrar algún desarrollo de materias particulares que al jurista moderno pueden parecer, en diferentes sentidos, afines o próximas; y que por tanto requieren aguzar el análisis para tratar de indagar si tras ellas podría encontrarse, aunque fuera de manera solapada o indirecta, algún indicio de tratamiento de la cuestión de las impensas.

Tal es el caso de la existencia de algunas disposiciones legislativas en las que se utiliza el término impensae -o alguno de sus derivados ${ }^{10}$ - y sinónimos; algunos

${ }^{8}$ Girard, Paul-Frédéric, cit. (n. 1), pp. 368-369; Riccobono, Salvatore, Il compenso per spese fatte da possessori su cose altrui, cit. (n. 1), pp. 6-7; Riccoвono, Salvatore, Distinzione delle impensae e la regola fructus intelliguntur deductis impensis, cit. (n. 1), p. 74; RicCOBONO, Salvatore, Dal Diritto romano classico al diritto moderno. A proposito di D. 10, 3, 14 [Paul. 3 ad Plautium], en El Mismo, Scr. di diritto romano (1917, reimp. Palermo, Università degli Studi, 1964), II, pp. 16 n. 1, 175, 325 y 380; Biondi, Biondo, cit. (n. 1), p. 278 y n. 114; Bonfante, Pietro, Corso di Diritto Romano, I, cit. (n. 1), p. 463; LATORRE, Ángel, Voluntas mulieris y reembolso de las impensas útiles dotales, en IURA, 5 (1954), p. 210.

9 Vid., por todos, Riccobono, Salvatore, Gli Scholii Sinaitici, en BIDR, 9 (1896), p. 230; Riccobono, Salvatore, Distinzione delle impensae e la regola fructus intelliguntur deductis impensis, cit. (n. 1), pp. 78-79; Riccoвono, Salvatore, Tracce di diritto romano classico nelle collezioni guiridiche bizantine, en BIDR, 18 (1906), p. 197; SCHULZ, Fritz, Impensae necessariae dotem ipso iure minuunt, en ZSS, r. A., 34 (1913), p. 102; RICCA-BARBERIS, Mario, Le spese sulle cose immobili e il loro risarcimento (Torino, Unione Tipografico-Editrice Torinese, 1914), p. 4; LÉVY, Jean-Philippe, Les impenses dotales en droit romain classique (Paris, Librarie du Recueil Sirey, 1937), pp. 90-91; v. spese, GuARneri CitATI, Andrea, cit. (n. 2), p. 723; LATORRE, Ángel, cit. (n. 8), pp. 209-212; NiEDERLÄNDER, Hubert, Zur Herkunft der römischen Impensen-Dreiteilung, en ZSS. r. A., 75 (1958), pp. 201-219; RESZCZY SKI, Jaroslaw, Impendere, Impensa, Impendium, en SDHI, 55 (1989), pp. 224 ss.; GonzáleZ-Palenzuela, María Teresa, Las impensas en el Derecho Romano Clásico, cit. (n. 2), p. 124.

${ }^{10}$ Cfr. v. impensa vel inpensa, ae, f., Forcellini, Egidio, Lexicon Totius Latinitatis (1864, reimp. Patavii, Gregoriana, Arnaldus Forni Excudebat Bononiae, 1965), p. 735; v. impendere, inpendere, Heumann, Hermann-SECKel, Emil, Handlexikon zu den Quellen des römischen Recht (1907, reimp. Graz, Akademische Druck-u. Verlagsanstalt, 1971), pp. 248-249; v. impendo, is, dere, di, sum (de in y pendo), BláNQuez, Agustín, Diccionario Latín-Español (Barcelona, Editorial Ramón Sopena, 1985), p. 829; v. impendo, -dere, -di, -sum, tr. inp-, [in + pendo], GLARE, P. G. W., Oxford Latin Dictionary (1982, reimp. Oxford, Oxford University Press, 2009), I, p. 842; v. impendium (inp), sv. impensa (inp-), LeWIS, Charlton T.-SHOrT, Charles, A Latin Dictionary (1879, reimp. Oxford, Clarendon Press, 1988), pp. 898-899; v. im-pendeo, ere (in e pendeo), Calonghi, Ferruccio, Dizionario latino italiano ( $3^{\mathrm{a}}$ edición, Torino, Rosenberg \& Selier, 1990), col. 1321; v. impendo, -ere, -di, -sum [in, pendo], SEgURA, Santiago, Nuevo diccionario etimológico Latín-Español y de las voces derivadas (Bilbao, Universidad de Deusto, 2003), pp. 
provenientes de la raíz común ${ }^{*}$ pend- ${ }^{11}$ y otros distintos, tales como los términos erogare (erogatio) ${ }^{12}$, sumere (sumptus, insumptio, consumptio $)^{13}$ e incluso meliorare (melioratio $)^{14}$.

357-358; v. pendo, -is, pependi, pensum, pendere, Ernout, Alfred-Meillet, Antoine, Dictionaire etymologique de la langue latine (4a edición, Paris, Klincksiek, 2001), p. 495; v. impensae, ae, f., Castiglioni, Luigi-Mariotti, Scevola, IL. Vocabolario della Lingua Latina ( $3^{\mathrm{a}}$ edición, Torino, Loescher Editore, 1996), p. 594.

${ }^{11}$ Si se observan las fuentes literarias y jurídicas la terminología relativa a la realización de gastos puede agruparse, por un lado, en aquellas palabras provenientes de la raíz ${ }^{*}$ pend-, entre las cuales destaca especialmente, el verbo impendere, y sus sustantivos derivados, impensa e impendium, pero además se deben añadir el verbo sinónimo expendere y sus consiguientes sustantivos expensa y expensum, cfr. v. expensa, ae, f., ForCELLINI, Egidio, cit. (n. 10), p. 366; v. expendo, -dere, di, -sum [ex-+pendo], GLARE, P. G. W., cit. (n. 10), I, p. 648; v. ex-pendo, pendi, pensum, ere, CALONGHI, Ferruccio, cit. (n. 10), cols. 1042 y 1043; v. expensae, Berger, Adolf, Encyclopedic Dictionary of Roman Law (1953, reimp. Philadelphia, American Philosophical Society, 1991), p. 464; v. expensa ae.f. (sc. pecunia) [expendo], sv. expensum, LeWIs, Charlton T.-SHORT, Charles, cit. (n. 10), p. 693; v. expensa, ae, f., CASTIGLIONI, Luigi-MariotTi, Scevola, cit. (n. 10), p. 429; v. expendo, -ere, -di, -sum [ex, pendo], SEGURA, Santiago, cit. (n. 10), p. 267. Igualmente, los verbos dependere, con sus sustantivos depensio y depensum, y dispensare, del cual provienen dispensatio y dispendium, cfr. v. dependo, dis, di, sum, dere, a. 3. (de et pendo), ForCellini, Egidio, cit. (n. 10), p. 70; v. dispendium, ii, n. 2., ForCellini, Egidio, cit. (n. 10), p. 157 ; v. dependere, Heumann, Hermann-SECKel, Emil, cit. (n. 10), p. 136; v. dispendium, Heumann, Hermann-SECKel, Emil, cit. (n. 10), p. 151; v. depensio, onis, BlánQueZ, Agustín, cit. (n. 10), p. 502; v. dispendium, ii (de dispendo), BlánQueZ, Agustín, cit. (n. 10), p. 537; v. depensum (From dependere), Berger, Adolf, cit. (n. 11), p. 464; v. depensio, onis, $f$. [dependo], LeWIs, Charlton T.-SHORT, Charles, cit (n. 10), p. 549; v. dispendium, ii, $n$. [dispendo], v. dispensatio, onis, $f$. [dispenso], LEWIs, Charlton T.-Short, Charles, cit. (n. 10), p. 591; v. depensum, GutiérreZ-Alviz y Armario, Faustino, cit. (n. 2), p. 187; v. dependo, is, pendi, pensum, ere, 3. tr., Castiglioni, Luigi-Mariotti, Scevola, cit. (n. 10), p. 303; v. dispendium, ii, n., Castiglioni, Luigi-Mariotti, Scevola, cit. (n. 10), p. 335; v. dispendium, -i [dispendo], Segura, Santiago, cit. (n. 10), p. 226.

${ }^{12}$ Cfr. v. erogatio, onis, f. 3., ForCellini, Egidio, cit. (n. 10), p. 297; v. erogo, as, are, avi, atum (de e y rogo), BLÁNQUEZ, Agustín, cit. (n. 10), p. 643; v. erogatio; v. erogo, -are, -aui, -atum [ex- + rogo], GlaRe, P.G.W., cit. (n. 10), I, pp. 617-618; v. erogatio, onis, f. [erogo], v. erogo, avi, atum, LewIs, Charlton T.-SHORT, Charles, cit. (n. 10), p. 657; v. erogatio, onis, f., CAStiglioni, Luigi-MariotTI, Scevola, cit. (n. 10), p. 394; v. rogo, -as, -aui, -atum, -are, ERNOUT, Alfred-Meillet, Antoine, cit. (n. 10), pp. 575-576; v. erogo, -are, avi, atum, [e, rogo], SEGURA, Santiago, cit. (n. 10), p. 255.

${ }_{13}$ Cfr. v. sumptus, us, m. (sumo), Calonghi, Ferruccio, cit. (n. 10), col. 2655; v. sumptus, Berger, Adolf, cit. (n. 11), p. 724; v. sumptus, Heumann, Hermann-Seckel, Emil, cit. (n. 10), p. 569; v. sumptus, us (de sumo), BlánQueZ, Agustín, cit. (n. 10), p. 1654; v. sumptus (sumtus), -us, m. [sumo +-tus], Glare, P. G. W., cit. (n. 10), I, p. 1871; v. sumptus, us, LeWIs, Charlton T.-SHORT, Charles, cit. (n. 10), p. 1803; v. sumo, -is, sumpsi, sumptum, -ere, ERNoUT, Alfred-Meillet, Antoine, cit. (n. 10), p. 666; v. sumptus, -us [i], [sumo], SEgURA, Santiago, cit. (n. 10), p. 750 ; v. insumere, Heumann, Hermann-SeCKel, Emil, cit. (n. 10), p. 276; v. insumo, is, ere, mpsi, mptum, BláNQUEZ, Agustín, cit. (n. 10), p. 829; v. in-sumo, mpsi, mptum, LeWIS, Charlton T.-SHORT, Charles, cit. (n. 10), p. 972; v. insumo, -ere, -psi, -ptum [in, sumo], SEGURA, Santiago, cit. (n. 10), p. 385.

${ }^{14}$ Cfr. v. meliorare, Heumann, Hermann-Seckel, Emil, cit. (n. 10), p. 337; v. melioro, as, are (de melior), BlánQuez, Agustín, cit. (n. 10), p. 953; v. melior, -or, -us, a, Glare, P. G. W., cit. (n. 10), I, p. 1093; v. melioratio, onis, f. [melioro], LEWIs, Charlton T.-SHORT, Charles, cit. (n. 10), p. 1128. 
Más particularmente, una alusión aislada a los gastos en que incurrieron algunos ocupantes de tierras públicas distribuidas en época republicana, como se halla en la Lex Icilia de Aventino publicando, sobre la que conviene detenerse a observar si podría envolver una noticia sobre el tratamiento de las impensas en dicho periodo. Eso es lo que se verá a continuación.

\section{LA LEGISLACIÓN ARCAICA SOBRE OCUPACIÓN Y}

DISTRIBUCIÓN DE TIERRAS. INEXISTENCIA DE UN RÉGIMEN

DE REEMBOLSO

\section{Las leges regiae}

Una revisión general de la legislación monárquica, en busca de precedentes del tratamiento del reembolso de impensas, arrojan resultados que no son persuasivos en orden a su posible existencia.

Desde una mirada actual, se habría esperado encontrar en algunas leyes regias el uso de términos referidos al reembolso de gastos, o al menos el planteamiento de casos que sustancialmente hubieran correspondido a ello. Pero esto no ocurre.

No hay referencias de este tipo en las leyes de repartición de tierras de Rómulo, o a lo menos no es posible encontrarlas en las noticias que ofrecen historiadores como Dionisio de Halicarnaso ${ }^{15}$ y luego Plutarco ${ }^{16}$, además de otras fuentes literarias ${ }^{17}$.

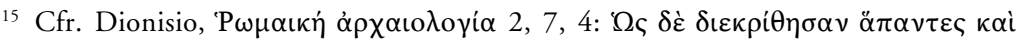

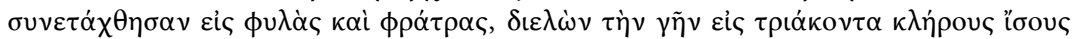

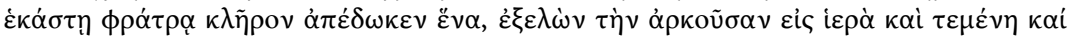

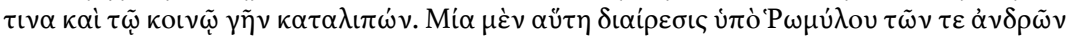

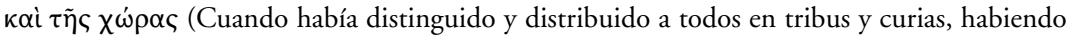
dividido la tierra en treinta lotes iguales, asignó uno a cada curia, excluyendo una extensión de tierra suficiente para los templos y los recintos sacros y reservándose una parte también para el uso público. Esta división, sea de los hombres, sea de la tierra, fue hecha por Rómulo); Dionisio,

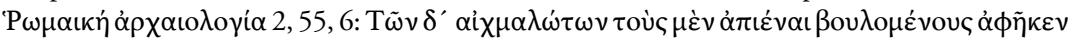

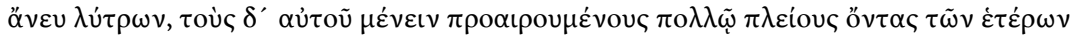

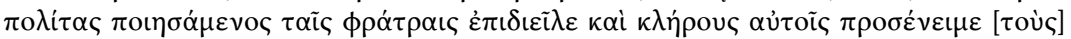

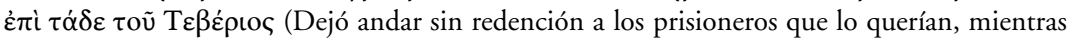
aquellos que preferían quedarse, que eran mucho más que los otros, después de hacerlos ciudadanos, les distribuyó entre las curias y asignó sus lotes de tierras en este lado del Tíber), para la traducción de las fuentes griegas se tuvo a la vista, Dionisio de Halicarnaso, Historia Antigua de Roma (Jiménez, Elvira-Sánchez, Ester (traductores), Madrid, Editorial Gredos, 1998), I, pp. 167 y 223; Franciosi, Genaro, Leges Regiae (Napoli, Dott. Eugenio Jovene, 2003), pp. 55-56.

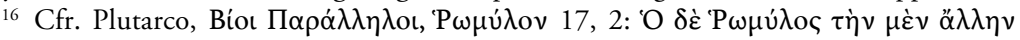

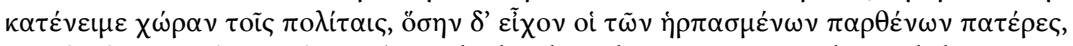

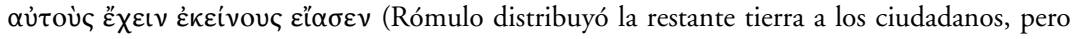
aquella que tenían los padres de las niñas secuestradas, les permitió conservarla), para la traducción de la fuente griega se tuvo a la vista, Franciosi, Genaro, Leges Regiae, cit. (n. 15), p. 55.

${ }_{17}$ Cfr. Varrón, Rerum rusticarum 1, 10, 2: bina ingera quod a Romulo primum divisa dicebantur viritim, quae heredem sequerentur, heredium appellarunt; Festo-Paulo, sv. Centuriatus (L. 47): centuriatus ager in ducena iugera definitus, quia Romulus centenis civibus ducena iugera tribuit...; Siculo Flaco, De condicionibus agrorum 118, 1: Centuriis, quarum mentionem nunc 
Lo mismo ocurre con Numa Pompilio cuando se revisan las leyes sobre la posterior distribución o delimitación de las tierras a las que se refieren Cicerón ${ }^{18}$, el mismo Dionisio ${ }^{19}$ y Plutarco ${ }^{20}$, más allá de las sabidas controversias sobre la historicidad de estas leyes ${ }^{21}$.

facimus, uocabulum datum est ex eo, <quod $>$ cum antiqui [Romanorum] agrum ex hoste captum uictori populo per bina ingera partiti sunt, centenis hominibus ducentena ingera dederunt: et ex hoc facto centuria iuste appellata est, vid. FrancIOSI, Genaro, Leges Regiae, cit. (n. 15), pp. 56-57.

${ }_{18}$ Cfr. Cicerón, De Re Publica 2, 14, 26: Ac primum agros quos bello Romulus ceperat divisit viritim civibus, vid. Franciosi, Genaro, Leges Regiae, cit. (n. 15), p. 119.

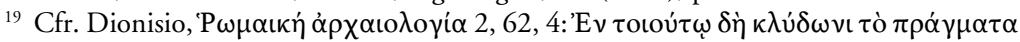

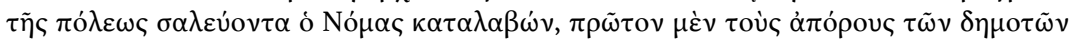

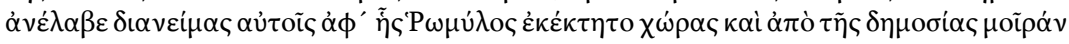

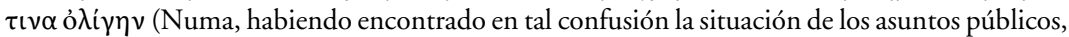
primero alivió a los plebeyos más pobres distribuyéndoles una pequeña parte de las tierras que ha-

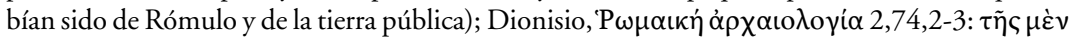

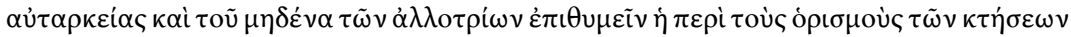

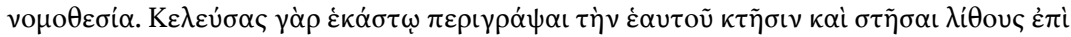

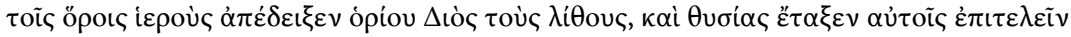

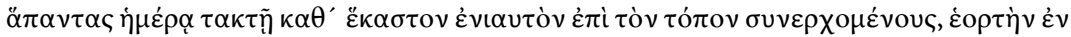

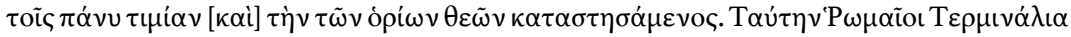

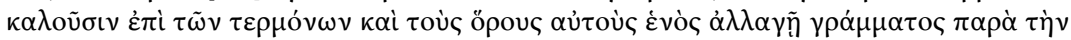

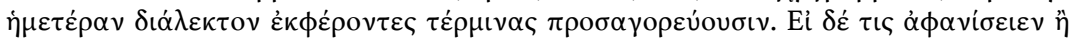

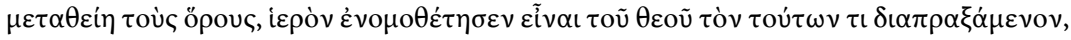

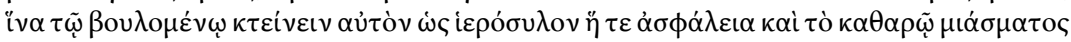
عĩvaı $\pi \rho \circ \tilde{\eta}$ (La ley relativa a la delimitación de las posesiones, tenía por objeto que las personas fueran felices y ninguno desease los bienes del otro. Habiendo en efecto ordenado a todos que trazaran una línea para delimitar sus propias tierras y poner piedras en sus fronteras, consagró estas piedras a Júpiter Terminalis y dispuso que todos, reuniéndose en el lugar, cumplieran todos los años, en un día establecido, sacrificios para él, instituyendo así una fiesta muy importante para la divinidad de las fronteras. Los romanos la llaman terminalia...), para la traducción de la fuente griega se tuvo a la vista, Dionisio de Halicarnaso, Historia Antigua de Roma, cit. (n. 15), I, pp. 231 y 247; Franciosi, Genaro, Leges Regiae, cit. (n. 15), pp. 119-120.

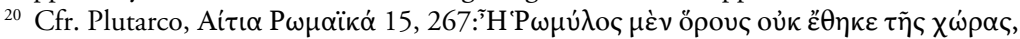

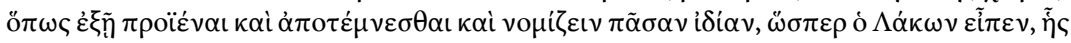

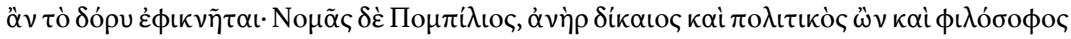

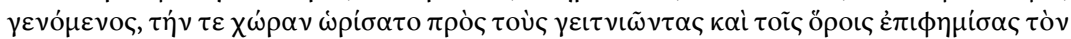

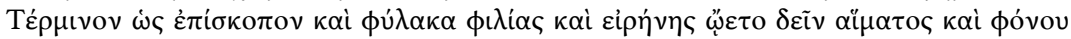

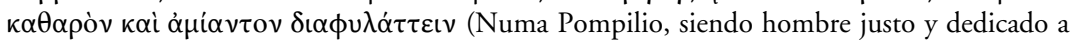
los asuntos públicos y convertido en amante de la sabiduría, delimitó las tierras entre los vecinos $\mathrm{y}$, habiendo asignado a los vecinos Termine como guardianes y custodios de la amistad y de la paz, considera necesario mantenerlo puro de la sangre del homicidio), vid. FranCIOSI, Genaro, Leges Regiae, cit. (n. 15), pp. 120-121.

${ }^{21}$ Vid., por todos, IHERING, Rudolf, Geist des römischen Rechts auf den verschiedenen Stufen seiner Entwicklung (2a edición, Leipzig, Druck und Verlag von Breitkopf und Härtel, 1866), I, pp. 198-205; MommSen, Theodor, Römisches Staatsrecht (3a edición, Leipzig, Hirzel, 1887), III, pp. 165-167; Karlowa, Otto, Römische Rechtsgeschichte (Leipzig, Verlag von Veit \& Comp., 1901), II, pp. 350-352; Bonfante, Pietro, Corso di Diritto Romano, II: La propietà (Milano, Dott. A. Giuffrè Editore, 1966), p. 251; DıósDI, György, Ownership in Ancient and Preclassical Roman Law (Budapest, Akadémiai Kiadó, 1970), pp. 34-36; DreYFus, Robert, Essai sur les lois agraires sous la république romaine, (1898, reimp. Roma, L’Erma di Bretschneider, 1971), pp. 7-11; MASCHKE, Richard, Zur Theorie und Geschichte der Römischen Agrargesetze (1906, reimp. 


\section{La legislación republicana}

En la época republicana, tal como ocurría en la monárquica, tampoco hay referencias legislativas al reembolso de las impensas. Pero a diferencia de aquella, en ésta ya aparecen ciertos giros lingüísticos o expresiones que nos aproximan algo más a la materia.

A este respecto, hay que evitar el influjo de la mera apariencia del lenguaje (habitualmente perteneciente a un comentarista posterior), de modo que en esta época se debe ser cauto ante la presencia del uso del verbo impendere y sus derivados, además de sus sinónimos expendere y sumptus: éstos carecen todavía del significado de "gasto reembolsable" y, en cambio, su significado de "desembolso" alcanza apenas un valor genérico y exorbitante.

Esto puede apreciarse, por ejemplo, en algunos pasajes de la Ley de las XII Tablas (451-450 a. C.). En la Tabla 10,322 sobre los gastos fúnebres se dice: Extenuato igitur sumptu tribus reciniis et tunicula purpurea... Y en la Tabla $12,1^{23}$, en la que se regula el procedimiento de la legis actio per pignoris capionem, se dijo:... quod quis ideo locasset, ut inde pecuniam acceptam in dapem, id est in sacrificium, impenderet.

Como se señaló, los usos que aquí se hacen de sumptus e impendo sólo se refieren al hecho mismo de "gastar" o realizar un "gasto", con el valor de realizar una ofrenda fúnebre o un sacrificio (in sacrificium, impenderet). Precisamente por su naturaleza común de rito o sacrificio ofrecido, no se podría pretender ningún reembolso por dicha impensa, y de allí que no tengan estas expresiones ninguna relevancia en lo que ahora se trata.

Fuera del código decenviral, la búsqueda de algún vestigio del tratamiento de

Napoli, Dott. Eugenio Jovene, 1980), pp. 14 ss.; CAPOgrossi-Colognesi, Luigi, La terra in Roma antica: forme di proprietà e rapporti produttivi (Roma, La Sapienza Editrice, 1981), pp. 110 ss. y 236 ss.; Behrends, Okko, La mancipatio nelle XII Tavole, en IURA, 33 (1982), p. 86; Capogrossi-Colognesi, Luigi, Cittadini e territorio. Consolidamento e trasformazione della 'civitas Romana' (Roma, La Sapienza Editrice, 2000), pp. 229-230; Salazar Revuelta, María, Evolución histórico-jurídica del condominio en el Derecho romano (Jaén, Universidad de Jaén, 2003), p. 56; FUENTESECA, Margarita, La formación romana del concepto de propiedad (Madrid, Dykinson, 2004), p. 12; AmunÁTEGUI, Carlos, El origen de los poderes del "paterfamilias". I. El "paterfamilias" y la "patria potestas", en REHJ, 28 (2006), pp. 92-94; CAPOGROSSI-CologNESI, Luigi, Diritto e potere nella storia di Roma (Napoli, Dott. Eugenio Jovene, 2007), pp. 11-49; SERrao, Feliciano, Diritto privato economia e società nella storia di Roma (Napoli, Dott. Eugenio Jovene, 2008), I, pp. 69-72; AmunÁTEGUI, Carlos, Las "gentes" y la propiedad colectiva, REHJ, 32 (2010), pp. 39-58 (especialmente pp. 40-41); AmunÁtegui, Carlos, The Collective Ownership and Heredium, en RIDA, 57 (2010), pp. 54-56; AmUnÁTEGUI, Carlos, Las relaciones entre el mercado y la propiedad en el Lacio primitivo, REHJ, 36 (2014), pp. 44-45.

${ }^{22}$ Cicerón, De Legibus 2, 23, 59: Extenuato igitur sumptu tribus reciniis et tunicula purpurea et decem tibicinibus tollit etiam lamentationem, cfr. FIRA (Florentiae, apud S. A. G. Barbèra, 1968), I, p. 66.

${ }^{23}$ Gayo, Inst. 4, 28: Lege autem introducta est pignoris capio, veluti lege XII tab. adversus eum, qui hostiam emisset nec pretium redderet; item adversus eum, qui mercedem non redderet pro eo iumento, quod quis ideo locasset, ut inde pecuniam acceptam in dapem, id est in sacrificium, impenderet, cfr. FIRA, cit. (n. 22), I, p. 72. 
la restitución de las impensas en las leyes agrarias de comienzos de la República también parecería vana.

Por señalar a título ilustrativo algunas de las leyes de este ámbito que se han revisado, puede hacerse reenvío a la Lex Cassia agraria (486 a. C.) ${ }^{24}$; la Rogatio Agraria de 484 a. C. ${ }^{25}$; la Rogatio Fabia agraria (477 a. C.) ${ }^{26}$; la Rogatio Considia Genucia agraria (476 a. C.) ${ }^{27}$; la Rogatio agraria de 471 a. C. ${ }^{28}$; la Rogatio Aemilia agraria (467 a. C.) ${ }^{29}$; la Rogatio Poetelia agraria (441 a. C.) ${ }^{30}$; la Rogatio Maelia agraria (436 a. C.) ${ }^{31}$; la Rogatio agraria de 418 a. C. ${ }^{32}$; la Rogatio agraria de 417

${ }^{24}$ Livio, Ab Urbe condita libri 2, 41: Tum primum lex agraria promulgata est, numquam deinde usque ad hanc memoriam sine maximis motibus rerum agitata, cfr. NISARD, Désiré, Collection des Auteurs Latins, Oeuvres de Tite-Live (París, Chez Firmin Didot Fréres, 1864), I, p. 89. Vid., por todos, Mommsen, Theodor, Römische Geschichte (5a edición, Berlin, Wiedmannsche Buchhandlung, 1869), III, pp. 282-283; PAIS, Ettore, Storia di Roma (Torino, Carlo Clausen, 1898), I, pp. 432-504; D'IPpolito, Federico, In recent years credulity has taken over again, en Labeo, 21 (1975), pp. 197-210; De Sanctis, Gaetano, Sul 'foedus Cassianum', en El Mismo, Scr. Minori (1929, reimp. Roma, Edizioni di Storia e Letteratura, 1976), IV, pp. 321-328; CAPANELli, Daniele, Appunti sulla Rogatio Agraria di Spurio Cassio, en Legge e società nella repubblica romana (Napoli, Jovenne Editore, 1981), I, pp. 3-50; SERRAO, Feliciano, Lotte per la terra e per la casa a Roma dal 485 al 441 a. C., en EL Mismo (editor), Legge e società nella repubblica romana (Napoli, Jovenne Editore, 1981), I, pp. 51-196; RoTONDI, Giovanni, Leges publicae populi romani (1912, reimp. Hildesheim-Zürich-New York, Georg Olms Verlag, 1990), pp. 194-195; GaBA, Emilio, Roma Arcaica. Storia e Storiografia (1964, reimp. Roma, Edizioni di Storia e Letteratura, 2000), pp. 129 ss. (especialmente pp. 129-140).

${ }^{25}$ Livio, Ab Urbe condita libri 2, 42: Sollicitati et eo anno sunt dulcedine agrariae legis animi plebis. Tribuni plebi popularem potestatem lege populari celebrabant; patres satis superque gratuiti furoris in multitudine credentes esse, largitiones temeritatisque inuitamenta horrebant, cfr. NISARD, Désiré, cit. (n. 24), I, p. 90.

${ }^{26}$ Livio, Ab Urbe condita libri 2, 48: Itaque principio anni censuit, priusquam quisquam agrariae legis auctor tribunus existeret, occuparent patres ipsi suum munus facere, captiuum agrum plebi quam maxime aequaliter darent: uerum esse habere eos, quorum sanguine ac sudore partus sit, cfr. NisARD, Désiré, cit. (n. 24), I, p. 96.

${ }^{27}$ Livio, Ab Urbe condita libri 2, 52: ... Tribuni plebem agitare suo ueneno, agraria lege; in resistentes incitare patres nec in uniuersos modo sed in singulos, NISARD, Désiré, cit. (n. 24), I, p. 100.

${ }^{28}$ Livio, Ab Urbe condita libri 2, 54: L. Furius inde et C. Manlius consules. Manlio Veientes prouincia euenit. Non tamen bellatum; indutiae in annos quadraginta petentibus datae frumento stipendioque imperato. Paci exteruae confestim continuatur discordia domi. Agrariae legis tribuniciis stimulis plebs furebat, NiSARD, Désiré, cit. (n. 24), p. 101.

${ }^{29}$ Livio, Ab Urbe condita libri 3, 1: Iam priore consulatu Aemilius dandi agri plebi fuerat auctor..., NisARD, Désiré, cit. (n. 24), p. 110.

${ }^{30}$ Livio, Ab Urbe condita libri 4, 12: qui tribunus plebis iterum ea ipsa denuntiando factus, neque ut de agris diuidendis plebi referrent consules ad senatum peruincere potuit..., NISARD, Désiré, cit. (n. 24), I, p. 180.

${ }^{31}$ Livio, Ab Urbe condita libri 4, 21: ... ab Sp. Maelio tribuno plebis, qui fauore nominis moturum se aliquid ratus et Minucio diem dixerat et rogationem de publicandis bonis Seruili Ahalae tulerat, NiSARD, Désiré, cit. (n. 24), I, p. 187.

${ }^{32}$ Livio, Ab Urbe condita libri 4, 43: Excipiunt omissam tribuni, aliaeque subinde, inter quas et agrariae legis, seditiosae actiones exsistunt..., NISARD, Désiré, cit. (n. 24), I, p. 204. 
a. C. ${ }^{33}$; la Rogatio Maecilia Metilia agraria (416 a. C. $)^{34}$; la Rogatio Sextia agraria (414 a. C.) $)^{35}$; la Rogatio Icilia agraria (412 a. C.) ${ }^{36}$; la Rogatio Maenia agraria (411 a. C. $)^{37}$; la Rogatio agraria de 397 a. C. ${ }^{38}$; la Rogatio agraria de 387 a. C. ${ }^{39}$; hasta la Lex Liciniae Sextiae de modo agrorum (367 a. C. $)^{40}$.

Comparecen aquí en ocasiones los términos impensa y algunos de sus sinónimos; pero no con el sentido de gasto jurídicamente reembolsable, ni con alguno de carácter técnico que sea de interés.

Así, por ejemplo, se encuentra el término sumpta a propósito del gasto realizado en las armas en la Rogatio Licinea agraria del año 482 a. C. de la que se tiene noticias por Livio, $A b$ Urbe condita libri 2, $43^{41}$ : Eo anno non segnior discordia domi et bellum foris atrocius fuit. Ab Aequis arma sumpta...; y luego, en la misma rogatio, el de impendiam para referirse al gasto en cosas militares: uenisse tempus ratus per ultimam necessitatem legis agrariae patribus iniungendae, susceperat rem militarem impediendam.

33 Livio, Ab Urbe condita libri 4, 44: Subinde ab iisdem tribunis mentio in senatu de agris diuidendis inlata est, cui actioni semper acerrime $C$. Sempronius restiterat, ratis, id quod erat, aut deposita causa leuiorem futurum apud patres reum aut perseuerantem sub iudicii tempus plebem offensurum. NisARD, Désiré, cit. (n. 24), I, pp. 205-206.

${ }^{34}$ Livio, Ab Urbe condita libri 4, 48: Ei cum rogationem promulgassent ut ager ex hostibus captus uiritim diuideretur, magnaeque partis nobilium eo plebiscito publicarentur fortunae -nec enim ferme quicquam agri, ut in urbe alieno solo posita, non armis partum erat, nec quod uenisset adsignatumue publice esset praeterquam plebs habebat-, NiSARD, Désiré, cit. (n. 24), I, p. 208.

${ }^{35}$ Livio, Ab Urbe condita libri 4, 49: Auxit eam iram, postquam ab collegis arcessitus propter seditiones tribunicias in urbem reuertit, audita uox eius in contione stolida ac prope uecors, qua M. Sextio tribuno plebis legem agrariam ferenti, NiSARD, Désiré, cit. (n. 24), I, p. 210.

${ }^{36}$ Livio, Ab Urbe condita libri 4, 52: Is cum principio statim anni, uelut pensum nominis familiaeque, seditiones agrariis legibus promulgandis cieret, NISARD, Désiré, cit. (n. 24), I, p. 212.

${ }^{37}$ Livio, Ab Urbe condita libri 4, 53: ... dilectum habentem Valerium consulem M. Menenius tribunus plebis legis agrariae lator cum impediret auxilioque tribuni nemo inuitus sacramento diceret, NisARD, Désiré, cit. (n. 24), I, p. 213.

${ }^{38}$ Livio, Ab Urbe condita libri 5, 12: Victores tribuni ut praesentem mercedem iudicii plebes haberet legem agrariam promulgant, tributumque conferri prohibent..., NISARD, Désiré, cit. (n. 24), I, p. 232.

39 Livio, Ab Urbe condita libri 6, 5: Iam et tribuni plebis ciuitate aedificando occupata contiones suas frequentare legibus agrariis conabantur, NISARD, Désiré, cit. (n. 24), I, p. 274.

${ }^{40}$ Livio, Ab Urbe condita libri 6, 35: ... alteram de modo agrorum, ne quis plus quingenta iugera agri possideret, NiSARD, Désiré, cit. (n. 24), I, p. 300; Valerio Máximo, Factorum ac dictorum memorabilium 8, 6, 3: Gaius uero Licinius Stolo, cuius beneficio plebi petendi consulatus potestas facta est, cum lege sanxisset ne quis amplius quingenta agri iugera possideret, ipse mille conparauit dissimulandique criminis gratia dimidiam partem filio emancipauit. quam ob causam a. M. Popilio Laenate accusatus primus sua lege cecidit ac docuit nihil aliud praecipi debere, nisi quod prius quisque sibi imperauerit, KeMPF, Karl, Valeri Maximi Factorum et dictorum memorabilium libri novem (Berolini, Impensis Georgii Reimeri, 1854), p. 620; HaLm, Karl, Valeri Maximi Factorvm et dictorvm memorabilivm: libri Novem (Lipsiae, In aedibvs Tevbnerianis, 1865), pp. 389-390; Aulo Gelio, Noctes Atticae 20. 1. 23: Quid salubrius uisum est rogatione illa Stolonis ingerum de numero praefinito?, Goold, G.P., The Loeb Classical Library, The Attic Nights of Aulus Gellius (1927, reimp. Rolfe, John C. (traductor), Harvard University Press, Cambridge-Massachusetts-London, 1993), p. 414.

${ }^{41}$ NiSARD, Désiré, cit. (n. 24), I, p. 91. 
Este último, ahora como impediret, se encuentra en la Rogatio Maenia agraria (411 a. C.), de la que informa nuevamente Livio 4, 53 $3^{42}$... dilectum habentem Valerium consulem M. Menenius tribunus plebis legis agrariae lator cum impediret auxilioque tribuni nemo inuitus sacramento diceret, y en la Rogatio agraria del 387 a. C. ${ }^{43}$ : Haud magno opere plebem mouerunt et infrequentem in foro propter aedificandi curam et eodem exhaustam impensis eoque agri immemorem, ad quem instruendum uires non essent.

También se usa inpendiit en la Rogatio Pontificia agraria de 481 a. C., para referirse a los tributos gastados, como aparece en Livio 2, $44^{44}$ : uelut processisset Sp. Licinio, ingressus dilectum paulisper inpediit.

Por su parte en la Rogatio Aemilia Fabia agraria del año 464 a. C., se encuentra el verbo expendere simplemente como gasto en las cosas en Livio, 3, $1^{45}$ : Atrox certamen aderat, ni Fabius consilio neutri parti acerbo rem expedisset; y el de erogare en la Rogatio agraria de 421 a. C. para referirse al estipendio militar que se paga al estado en Livio, 4, 36 $6^{46}$ : Agri publici diuidendi coloniarumque deducendarum ostentatae spes et uectigali possessoribus agrorum imposito in stipendium militum erogandi aeris.

En suma, este panorama general da cuenta de una ausencia de vestigios arcaicos de alguna forma de reembolso de gastos. Sin embargo, hay una referencia en la legislación republicana que requiere de un tratamiento particular: la Lex Icilia de Aventino publicando.

\section{LOS GASTOS DE EDIFICACIÓN EN LA LEX ICILIA DE AVENTINO PUBLICANDO}

Más allá de que, sobre la base de los antecedentes generales apenas revisados, y que no pueda decirse que haya existido una disciplina arcaica de las impensae, se debe aceptar la fuerza, que al menos a primera vista, tienen las noticias sobre la Lex Icilia de Aventino publicando del año 456 a. C. ${ }^{47}$, entregadas por Dionisio

${ }^{42}$ NiSARD, Désiré, cit. (n. 24), I, p. 213.

43 Tito Livio, Ab Urbe condita libri 6. 5, vid. NisARD, Désiré, cit. (n. 24), I, p. 274.

${ }^{4}$ NisARD, Désiré, cit. (n. 24), I, p. 92.

45 Cfr. Nisard, Désiré, cit. (n. 24), I, p. 110.

46 Cfr. Nisard, Désiré, cit. (n. 24), I, p. 199.

47 Vid., por todos, MACÉ, Antonin, Des lois agraires chez les romains (Paris, Joubert, 1846), pp. 138 n. 3 y 167-172; SCHWEGLER, Albert, Römische Geschichte im zeitalter des Kampfs der Stände (2a edición, Tübingen, Verlag der H. Laupp'schen Buchhandlung, 1870), II, pp. 598602; Lange, Ludwig, Römische Alterthümer (3a edición, Berlin, Weidmannsche Buchhandlung, 1876), I, pp. 603-605; Mommsen, Theodor, Römisches Staatsrecht, cit. (n. 21), pp. 166 n. 1; MeYer, Eduard, Der Ursprung des Tribunats und die Gemeinde der Vier Tribus, en Hermes, 30 (1895), pp. 12-13; Merlin, Alfred, L'Aventin dans l'antiquité (Paris, Albert Fontemoing, 1906), pp. 69-91; Binder, Julius, Die Plebs. Studien zur römischen Rechtsgeschichte (Leipzig, A. Deichert' sche Verlagsbuchhandlung Nachf, 1909), pp. 87 y 473 ss.; CosTA, Emilio, Storia del diritto romano privato (Milano, Fratelli Bocca, 1911), p. 189 (especialmente n. 1); DrEYFus, Robert, cit. (n. 21), pp. 48-50; ELSTER, Marianne, Studien zur Gesetzgebung der frühen römischen Republik-Gesetzesanhäufungen und-wiederholungen (Bern, Peter Lang Frankfurt/M., 1976), pp. 90-91; MASCHKE, Richard, cit. (n. 21), pp. 50-52; SERRAO, Feliciano, Lotte per la terra e per la 


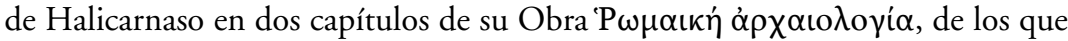
destaca $10,32,2^{48}$ :

$\Omega \varsigma \delta^{\prime} \dot{\alpha} \pi \varepsilon \lambda \dot{\sigma} \sigma \alpha \tau o \tau \alpha u ́ \tau \alpha \varsigma \tau \grave{\alpha} \varsigma$

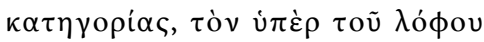

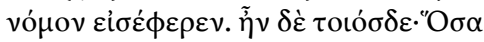

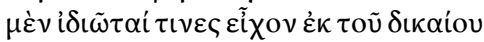

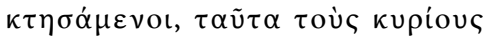
$\kappa \alpha \tau \varepsilon \dot{\chi} \chi \varepsilon เ v \cdot$ ö $\sigma \alpha \delta \dot{\varepsilon} \beta \iota \alpha \sigma \alpha \dot{\alpha} \mu \varepsilon v o ̛ ́ ~ \tau \iota v \varepsilon \varsigma$

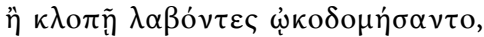
$\kappa о \mu \iota \sigma \alpha \mu \varepsilon \dot{v o v \varsigma} \tau \dot{\alpha} \varsigma \delta \alpha \pi \alpha \dot{\alpha} v \alpha \varsigma, \ddot{\alpha} \varsigma$ $\ddot{\alpha} v$ oi $\delta \iota \alpha \iota \tau \eta \tau \alpha \grave{i} \gamma v \tilde{\omega} \sigma \iota, \tau \tilde{\omega} \delta \eta \dot{\mu} \mu \omega$

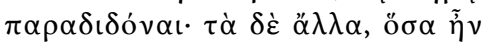

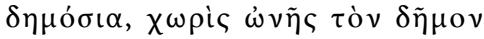
$\pi \alpha \rho \alpha \lambda \alpha \beta \operatorname{vov} \tau \alpha \delta \varepsilon \lambda \varepsilon \dot{\varepsilon} \sigma \alpha \alpha$.
Después de haber respondido estas acusaciones, él [Icilio] procedió a promover su ley respecto al monte [Aventino]. Era de tal forma: En cuanto, para todas las parcelas de terreno poseídas por algunos particulares, si fueron aquellas obtenidas en derecho, que tales poseedores las conserven. En cuanto a los otros, quienes habían construido con fuerza o usurpación, habrán de entregar los terrenos al pueblo, si se les reembolsan las expensas, según el conocimiento de los árbitros. En cuanto, respecto de todo el resto, que era público, sin pago del precio, debía ser recibido y dividido en parcelas para el pueblo ${ }^{49}$.

casa a Roma dal 485 al 441 a. C., cit. (n. 24), I, pp. 121 ss.; NATElson, Robert, Comments on the Historiography of Condominium: The Myth of Roman Origin, en Oklahoma City University Law Review, 12 (1987), I, pp. 43-46; Rotond, Giovanni, cit. (n. 24), pp. 199-200; Oliviero, Giuseppina, La 'lex Icilia de Aventino publicando', en Index, 25 (1997), p. 521; SerRao, Feliciano, Diritto privato economia e società nella storia di Roma, cit. (n. 21), I, pp. 119-120; ROSELAAR, Saskia, Public Land in the Roman Republic (Oxford, Oxford University Press, 2010), p. 29; VAN Der Merwe, Cornelius, European Condominium Law (Cambridge, Cambridge University Press, 2015), p. 11; Cfr. Pernice, quien considera que se trata de atribuciones de tierras hechas por Tiberio Graco, Pernice, Alfred, Parerga, 2, Beziehungen des offentlichen romischen Rechts zum Privatrecht, ZSS, r. A. 5 (1884), p. 74.

${ }^{48}$ El contexto de la realización de esta propuesta se describe en la primera parte del pasaje

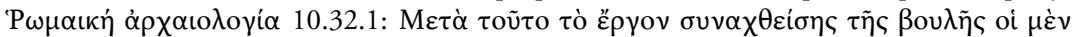

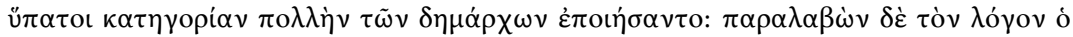

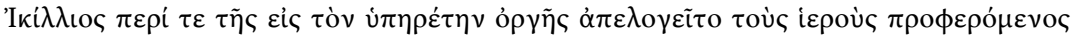

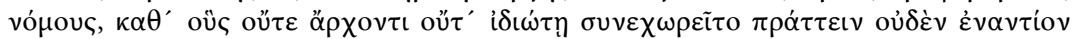

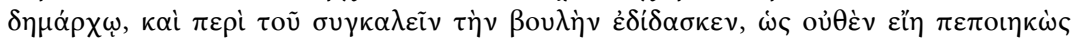

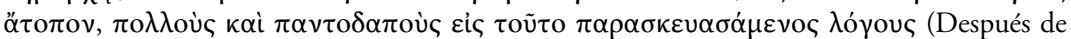
este asunto se reunió el Senado y los cónsules realizaron numerosas acusaciones contra los tribunos. Entonces Icilio, tomó la palabra, e intentó justificar la cólera que sentían hacia el lictor, apelando a las leyes sagradas que no permitían, ni a un magistrado ni a un particular, ofrecer cualquier oposición a un tribuno; y en cuanto al asunto de convocar al Senado, les indicó que no había hecho nada fuera de lugar, usando muchos argumentos de cualquier tipo, que había preparado antes), para la traducción de la fuente griega se tuvo a la vista, DENYS D'HALICARNASSE, Les antiquites romaines de Denys d'Halicarnasse (Mouchard, François-Camús, Alfredo-Lottin, Philippe-Nicolas (traductores), París, chez Philippe-Nicolas Lottin, 1723), II, p. 506; DionIsio de Halicarnaso, Historia Antigua de Roma (Jiménez, Elvira-Sánchez, Ester (traductores), Madrid, Editorial Gredos, 1998), IV, p. 57.

${ }^{49}$ Para la traducción de la fuente griega se tuvo a la vista, Mouchard-Camús-Lottin: “Après avoir répondu à ces deux chefs d'accusations, il parla de la loi qu'il prétendait établir. Elle portait: "que tous les biens, que les particuliers avaient acquis légitimement et de bon droit, devaient leur rester comme aux véritables possesseurs: mais que toutes les places dont quelques citoyens s'étaient mis en possession ou par force ou par fraude, et sur lesquelles ils avaient batti des maisons, seraient restituées au peuple, à condition qu'on rendrait aux usurpateurs, suivant l'arbitrage des experts, les 
Los pasajes del historiador de Halicarnaso relatan la propuesta hecha por el tribuno Lucio Icilio, para repartir las tierras del monte Aventino. Ésta habría tenido la finalidad, antes que todo política, de asegurar estas asignaciones a los plebeyos, de manera que ellos pudiesen construir allí sus casas ${ }^{50}$, todo en medio de la gran crisis económica y social que caracteriza el siglo $\mathrm{V}$ a. C. ${ }^{51}$.

dépenses qu'ils y avaient faites pour les bâtiments: qu'enfin tous les autres biens appartenant au public, seraient partagés entre le peuple sans, qu'il en payât rien»", DENYS D'HaLICARNASSE, Les antiquites romaines de Denys d'Halicarnasse, cit. (n. 48), II, p. 506; Serrao: "Le parti di terreno possedute dai privatti, a cui sono state divise secondo diritto, devono rimanere ai proprietari; le parcelle che alcuni, avendo occupato con la forza o possedendo con frode, abbiano edificato, devono essere restituite al popolo e gli attuali occupanti saranno rimborsati delle spese che gli arbitri abbiano stabilito; le altre parcelle che erano pubbliche deve dividerle il popolo acquistandole senza prezzo", SerRaO, Feliciano, Lotte per la terra e per la casa a Roma dal 485 al 441 a. C., cit. (n. 24), I, p. 125; Jiménez-Sánchez: "Cuando se hubo justificado de estas acusaciones, intentó introducir la ley relativa a la colina. Era asi: todo el terreno que tenían algunos particulares, si lo habian adquirido de forma justa, que lo siguieran conservando sus dueños; pero el que habian edificado algunos después de haberlo tomado por la fuerza o por robo, debian entregarlo al pueblo una vez que los nuevos dueños pagaran los costes que los árbitros decidiesen, y todo el terreno restante, que era público, el pueblo debia recibirlo sin pago y repartirselo", Dionisio de Halicarnaso, Historia Antigua de Roma, cit. (n. 48), pp. 57-58; Henderson: "After answering these accusations, he proceeded to introduce his law concerning the hill. It was to this effect: All the parcels of land held by private citizens, if justly acquired, should remain in the possession of the owners, but such parcels as had been taken by force or fraud by any persons and the present occupants reimbursed for their expenditures acoording to the appraisal of the arbitrators; all the remainder, belonging to the public, the populace should receive free of cost and divide up among themselves", HENDERSON, Jeffrey, The Loeb Classical Library. The Roman Antiquities (1947, reimp. Cary, Earnest (traductor), Cambridge-Massachusetts-London, Harvard University Press, 2002), pp. 274-277.

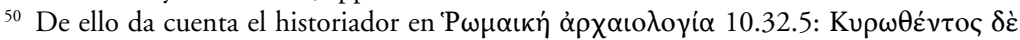

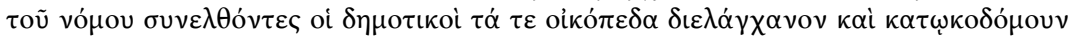

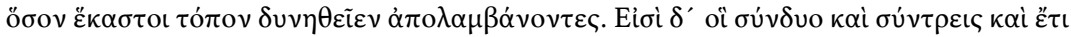

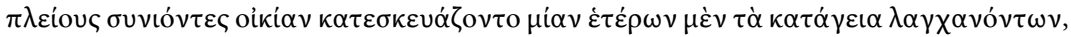

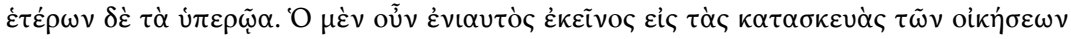
$\dot{\varepsilon} \delta \alpha \pi \alpha v \eta \dot{\theta} \eta$ (Cuando la ley se ratificó, se reunieron los plebeyos, dividieron los terrenos y empezaron a construir, cada uno tomando una parcela tan grande como pudo; y a veces dos, tres e incluso más juntos para construir una sola casa, y a unos les tocaba la parte de abajo y a otros la otra parte. Así pues, aquel año se empleó en la construcción de casas), para la traducción de la fuente griega se tuvo a la vista, Dionisio de Halicarnaso, Historia Antigua de Roma, cit. (n. 48), IV, p. 58. Vid., por todos, Rotond, Giovanni, cit. (n. 24), pp. 199-200; PASTORI, Franco, Prospettiva storica del diritto di superficies, en St. in memoria di Guido Donatuti (Milano, Cisalpino-La Goliardica, 1973), II, p. 874; NATELSON, Robert, cit. (n. 47), I, p. 43; Oliviero, Giuseppina, cit. (n. 47), p. 521; Roselaar, Saskia, cit. (n. 47), p. 29; Van Der Merwe, Cornelius, cit. (n. 47), p. 11; NATELSON, Robert, cit. (n. 47), I, pp. 43-44.

${ }^{51}$ Pareti, Luigi, Storia di Roma e del mondo romano (Torino, Unione Tipografico-Editrice Torinese, 1952), I, p. 392; DE MarTino, Francesco, Storia della costituzione romana (Napoli, Dott. Eugenio Jovene, 1972), I, p. 216; D’Ippolito, Federico, cit. (n. 24), p. 198; De MarTINO, Francesco, Storia económica di Roma antica (Firenze, La nuova Italia, 1979), I, pp. 13 ss.; RichaRDS, Jean-Claude, Les origines de la plèbe romaine. Essai sur la formation du dualisme patricio-plébéeien (Roma, École française, 1978), pp. 501 ss.; SerRAO, Feliciano, Lotte per la terra e per la casa a Roma dal 485 al 441 a. C., cit. (n. 24), I, pp. 121-180; ALFöLDI, Géza, Römische Sozialgeschichte ( $3^{a}$ edición, Wiesbaden, Franz Steiner Verlag GmbH, 1984), pp. 2126; Franciosi, Genaro, La plebe senza genti e il problema della rogatio Canuleia, en El Mismo 
Estas noticias se complementan con el breve relato que llega de la mano de Livio, en Ab Urbe condita libri 3, 31, 1:

Deinde M. Valerius Sp. Verginius consules facti. Domi forisque otium fuit; annona propter aquarum intemperiem laboratum est. De Auentino publicando lata lex est.
Entonces Marco Valerio y Espurio Verginio se hicieron cónsules. Hubo quietud en casa y en el extranjero. A causa del clima lluvioso se hacen escasas las provisiones. Se aprueba la ley del Aventino ${ }^{52}$.

Y luego en Ab Urbe condita libri 3, 32, 7:

Admiscerenturne plebeii controvérsia aliquamdiu fuit; postremo concessum patribus, modo ne lex Icilia de Aventino aliaeque sacratae leges abrogatur.
Hubo controversia un tiempo sobre si los plebeyos debían ser admitidos; al fin los patricios cedieron, siempre que la ley Icilia del Aventino y las demás leyes sagradas no se abolieran ${ }^{53}$.

La fuente de Livio, aunque da pocas luces de la repartición, confirma la noticia de Dionisio: que se trata de una propuesta realizada por el tribuno Icilio, según la fuente de una lex sacrata; y, en lo que importa, que se refiere a la atribución de las tierras del Aventino hecha a los plebeyos.

Ahora bien, no se puede dejar de mencionar la discusión que existe sobre la historicidad de esta $l e x^{54}$, en especial sobre su proceso constitucional y naturaleza;

(editor), Richerche sulla organizzazione gentilizia romana (Napoli, Dott. Eugenio Jovene, 1984), I, p. 162; Momigliano, Arnaldo, The Rise of the Plebs in the Archaic Age of Rome, en Raaflaub, Kurt (editor), Social Struggles in Archaic Rome: New Perspectives on the Conflict of the Orders (2a edición, Malden, MA, Blackwell Publishing, 2005), pp. 168-171; SerraO, Feliciano, Diritto privato economia e società nella storia di Roma, cit. (n. 21), I, pp. 115-122.

${ }^{52}$ Para la traducción de la fuente latina se tuvo a la vista, Nisard: "On créa ensuite consuls Cn. Valérius et Sp. Verginius. Au dedans comme au dehors tout fut tranquille; mais une disette de blé, causée par des pluies excessives, pesa sur le peuple, et on fit passer une loi qui lui partageait le mont Aventin", NisARD, Désiré, cit. (n. 24), I, p. 135.

${ }^{53}$ Para la traducción de la fuente latina se tuvo a la vista, Nisard: "Devaiton en choisir quelquesuns dans l'ordre des plébéiens? On agita longtemps cette question. Enfin on céda aux patriciens, à condition seulement que la loi Julia, au sujet du mont Aventin, et les autres lois sacrées, ne sauraient être abrogées". NisARD, Désiré, cit. (n. 24), I, p. 136.

${ }^{54}$ La doctrina es confusa en la apreciación de las noticias de Dionisio. Por una parte, se suele atribuir esta iniciativa al tribuno Icilio, dándole el carácter de plebiscito; por la otra, afirma que la lex, luego de la aprobación del senado fue sometida al voto de los comicios centuriados, vid., por todos, NiebuHr, Barthold Georg, Römische Geschichte (3a edición, Berlin, Verlag von G. Reiner, 1836), II, pp. 339-341; MACÉ, Antonin, cit. (n. 47), p. 169; IHne, Wilhelm, Römische Geschichte (Leipzig, Verlag von Wilhelm Engelmann, 1868), I, p. 159 n. 5; SCHWEgLER, Albert, cit. (n. 47), II, p. 603; LANGe, Ludwig, cit. (n. 47), I, pp. 603-605; Niese, Benedictus, Das sogenannte Licinisch-Sextische Ackergesetz, en Hermes, 23 (1888), pp. 410-423; MerLin, Alfred, cit. (n. 47), pp. 70-71; Binder, Julius, cit. (n. 47), pp. 473 ss.; PAreti, Luigi, cit. (n. 51), I, pp. 392-393; De Sanctis, Gaetano, Storia dei Romani (1907, reimp. Firenze, La Nuova Italia Editrice, 1960), p. 23 n. 74; Elster, Marianne, cit. (n. 47), pp. 90-91; Serrao, Feliciano, Lotte per la terra e per la casa a Roma dal 485 al 441 a. C., cit. (n. 24), I, pp. 123-139; Rotond, Giovanni, cit. (n. 24), pp. 199-200; RoselaAR, Saskia, cit. (n. 47), p. 29; NATELSON, Robert, cit. (n. 47), I, p. 45. 
pero tampoco de observar que ella se ha resuelto de manera afirmativa por la doctrina ${ }^{55}$. Incluso Maschke $e^{56}$, que atribuye a la más antigua legislación agraria el carácter de legendaria, sostiene la validez de la Lex Icilia de Aventino publicando, como el plebiscito que tiene por objeto conceder a los plebeyos un lugar para la construcción de sus casas; aunque considera que ninguna relación tiene con las leyes que son propiamente agrarias.

La primera dificultad que presenta esta fuente es que está escrita en griego y no hay terminología exacta que permita traducir los conceptos latinos en juego (verbos impendere, expendere y erogare, además de sus derivados, y otros términos ya revisados como sumptus).

Luego, en cuanto a su contenido, se suele distinguir en ella la atribución de tres categorías de terrenos ${ }^{57}$ : la primera, corresponde al terreno obtenido por

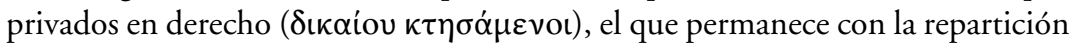
en manos de dichos poseedores. Éstas debieron ser las asignaciones del Aventino que en tiempos muy antiguos fueron hechas a la plebe, puesto que es la propia fuente la que informa que al momento de la repartición estaban ya habitados ${ }^{58}$.

En la segunda se encuentran los terrenos que algunos, probablemente patricios,

55 Schwegler, Albert, cit. (n. 47), II, p. 603; NieSE, Benedictus, cit. (n. 54), pp. 413 ss.; Pareti, Luigi, cit. (n. 51), I, p. 392; De Sanctis, Gaetano, Storia dei Romani, cit. (n. 54), II, p. 23 n. 74; Serrao, Feliciano, Lotte per la terra e per la casa a Roma dal 485 al 441 a. C., cit. (n. 24), I, pp. 123-139; Oliviero, Giuseppina, cit. (n. 47), pp. 531-532; RoselaAr, Saskia, cit. (n. 47), pp. 29-31.

${ }^{56}$ MaschKe, Richard, cit. (n. 21), pp. 50-52; en sentido similar, Serrao, Feliciano, Diritto privato economia e società nella storia di Roma, cit. (n. 21), I, p. 281. Cfr. De MarTino, Francesco, Nota di Lettura, en Maschke, Richard, Zur Theorie und Geschichte der Römischen Agrargesetze (1906, reimp. Napoli, Dott. Eugenio Jovene, 1980).

${ }^{57}$ Macé, Antonin, cit. (n. 47), p. 169; Merlin, Alfred, cit. (n. 47), p. 72; SERraO, Feliciano, Lotte per la terra e per la casa a Roma dal 485 al 441 a. C., cit. (n. 24), I, pp. 140 ss.; Oliviero, Giuseppina, cit. (n. 47), p. 528. Con algunas diferencia en las categorías, SCHWEgLER, Albert, cit. (n. 47), II, pp. 599-600.

58 Se suele pensar que ya en tiempos de Anco Marzio se habrían realizado estas antiguas asignaciones a los plebeyos, vid. por todos, NiebuHR, Barthold Georg, Römische Geschichte (4a edición, Berlin, Verlag von G. Reiner, 1833), I, pp. 335-336 y NiebuHr, Barthold Georg, Römische Geschichte, cit. (n. 54), p. 339; ElSTER, Marianne, cit. (n. 47), p. 90; RiCHARDS, JeanClaude, cit. (n. 51), pp. 270 ss.; SERRAO, Feliciano, Lotte per la terra e per la casa a Roma dal 485 al 441 a. C., cit. (n. 24), I, p. 142. Capogrossi-Colognesi, expone el marco que mantiene la historiografía de los ochenta destacando los siguientes aspectos: existe la gens que es titular de un territorio de su propiedad, que se puede identificar con la tierra gentilicia; el monopolio de estos terrenos lo detenta para el siglo $\mathrm{V}$ a. C. la aristocracia gentilicia; $y$, finalmente, los plebeyos son excluidos de hecho del ager publicus, hasta a lo menos la dictación de la Lex Licinie Sextie, vid. Capogrossi-Colognesi, Luigi, Cittadini e territorio. Consolidamento e trasformazione della 'civitas Romana', cit. (n. 21), pp. 263-265. Cfr. Oliviero, quien no está de acuerdo con dicha afirmación general: a su juicio no existen motivos válidos para excluir que los legítimos ocupantes del Aventino podían ser también los patricios, que sin haber edificado, se limitaban a poseer para ejercer la ganadería o con la perspectiva de poder construir una parte de su suelo, que era un territorio público y prevalentemente sin edificaciones, vid. Oliviero, Giuseppina, cit. (n. 47), p. 529. 


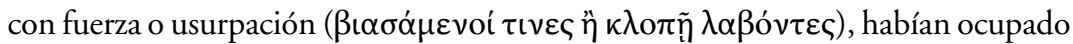
y edificado; con la repartición, este terreno se vuelve público ${ }^{59}$.

La tercera, se conforma por los terrenos públicos que no habían sido ocupados por nadie y que por la ley debían ser repartidos a la plebe sin que mediara pago de

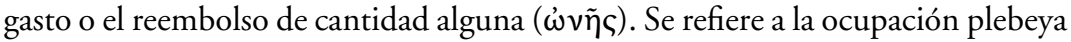
del ager publicus, y su triunfo por sobre los patricios, y este motivo ha sido el de mayor preocupación de la doctrina ${ }^{60}$.

La que interesa es la segunda categoría que, como advirtió ya Serrao ${ }^{61}$, es la que presenta mayores problemas. Según el propio Dionisio, se trata de aquellos terrenos que fueron adquiridos con fuerza o usurpación, y luego de que en ellos se hubo edificado, fueron atribuidos al pueblo y entregados a sus nuevos asignatarios

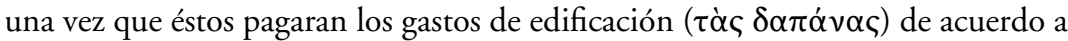
lo que estimaran los árbitros ( $\delta\llcorner\alpha \iota \tau \eta \tau \alpha i)$.

Son pocos los autores que han revisado este aspecto de la Lex Icilia de Aventino publicando. En su día, Schwegler ${ }^{62}$ sostuvo a propósito de esta repartición: el ager publicus (Gemeinland) en el que se encontraban particulares, debía ser confiscado por el Estado, debiendo los poseedores que han recuperado estas tierras, cuando se encuentren construidas, pagar una compensación razonable por dicha construcción que sería determinada por los árbitros. Pero, de manera errada, sostiene que sólo los poseedores de buena fe (redlichen) recibirán la compensación por dicha pérdida; no así aquellos no autorizados que adquirieron la posesión del ager publicus de mala fe (vi o clam).

En similar sentido, y por tanto incurre en la misma anticipación histórica que Schwegler, lo resuelve Niebuhr ${ }^{63}$, para quien la ley debió hacer distinción entre poseedores de buena y mala fe, y sólo los primeros tendrían derecho a una indemnización por los gastos en la construcción, los que debían ser pagados por los nuevos asignatarios de los terrenos.

Para Merlin ${ }^{64}$, la parte del pasaje referida al reembolso de los gastos se aplica a aquellas porciones de terrenos retenidas injustamente por particulares mediando fuerza o clandestinidad, habiendo éstos expulsado a los sus justos poseedores. A diferencia de los autores recién mencionados, sostiene que no era del todo improbable que se ofreciera una indemnización a poseedores vi o clam, puesto que los gastos habrían estado destinados a hacer la casa más habitable y productiva. Así,

59 PARETI, Luigi, cit. (n. 51), I, p. 392.

${ }^{60}$ Vid., por todos, SchWegler, Albert, cit. (n. 47), II, p. 602; Merlin, Alfred, cit. (n. 47), pp. 26-41 (especialmente pp. 38-40); Oliviero, Giuseppina, cit. (n. 47), p. 531; RoselaAr, Saskia, cit. (n. 47), pp. 29-31.

${ }^{61}$ Serrao, Feliciano, Lotte per la terra e per la casa a Roma dal 485 al 441 a. C., cit. (n. 24), I, p. 142.

62 Schwegler, Albert, cit. (n. 47), II, pp. 599-600.

63 Niebuhr, Barthold Georg, Römische Geschichte, cit. (n. 54), p. 339 n. 686.

${ }^{64}$ Se tratarían de los terrenos del ager publicus que habrían tomado los patricios por la fuerza o por clandestinidad, a sus vecinos pobres, y esta es justamente la situación que la lex busca remediar: busca devolver los terrenos y suprimir la posesión de hecho obtenida con violencia o fraude, Merlin, Alfred, cit. (n. 47), pp. 73-78. En este mismo sentido Pareti, Luigi, cit. (n. 51), I, p. 392. 
sería posible comprender que el legislador de la Lex Icilia, para evitar cualquier tipo de hostilidad de los patricios, otorgara el reembolso de los gastos de la construcción. Más aún, considera que no hay necesidad de distinguir, desde el punto de vista de la indemnización, entre los detentadores legales o ilegales del ager publicus; ni de suponer que lo establecido por la lex para esta categoría se habrían omitido por Dionisio, y que no serían aplicable a los poseedores de los agri privati.

En la doctrina actual el punto lo desarrolla con más detalle Serrao ${ }^{65}$ que, al igual que Merlin, estima que faltan motivos válidos para pensar que el texto referido por Dionisio no refleja -en esta parte-, el contenido sustancial de la ley. Sin perjuicio, en contra de propuestas como la de Schwegler y Niebuhr, excluye la posibilidad de retrotraer los principios del reembolso de las impensas de la reivindicatio clásica a la mitad del siglo $\mathrm{V}$ a. C.

Sin embargo, sostiene igualmente, que se trata de poseedores de mala fe a los cuales la ley despojaba de los terrenos que habían ocupado y las construcciones que habían hecho sobre ellos, estableciendo a su favor el reembolso de los gastos por la edificación, no empero del valor de la construcción (non, si badi, il rimborso del valore delle costruzioni). Los gastos estarían determinados por árbitros y serían los nuevos asignatarios quienes debían reembolsarlos ${ }^{66}$; y en parte parece decirlo así la lex cuando respecto de la tercera categoría establece que no se debe pagar precio alguno.

En suma, para este jurista, la única hipótesis posible de sustentar, es que la posibilidad de adquirir los terrenos construidos estaba limitada, puesto que las construcciones que allí se habían establecido habrían sido de cierta importancia y con ello, los gastos en los que debían incurrir los nuevos asignatarios habrían constituido por este motivo un gasto importante, sólo los plebeyos más ricos habrían podido acceder a ellos ${ }^{67}$. Existían dos sortitiones ${ }^{68}$ : una para los lotes gratuitos y otra para los lotes, tal vez más extensos y construidos, mediante el reembolso de los gastos establecidos por los árbitros.

Si se admite como cierta la fecha de la propuesta del tribuno Icilio, es difícil coincidir con cualquiera de estas propuestas doctrinarias, puesto que se fundan en anticipaciones históricas que no se pueden desatender.

65 Serrao, Feliciano, Lotte per la terra e per la casa a Roma dal 485 al 441 a. C., cit. (n. 24), I, pp. 142-145.

${ }_{66}$ También en este sentido, ya antes Niebuhr sostiene que el gasto de la construcción es de cargo del nuevo asignatario y no del Estado, NiebuHR, Barthold Georg, Römische Geschichte, cit. (n. 54), II, p. 339.

${ }^{67}$ Sin embargo, tampoco excluye que en ciertas ocasiones convenían también a los más pobres, por ejemplo porque las construcciones existían anteriormente y el reembolso de los gastos no era relevante, o porque la construcción era adaptada para que fuera habitada por varias familias, de acuerdo a lo señalado por Dionisio 10, 32, 5, que se refiere a todo el suelo, incluso a aquel que tiene construcciones, SERRAO, Feliciano, Lotte per la terra e per la casa a Roma dal 485 al 441 a. C., cit. (n. 24), I, p. 144 n. 236.

${ }^{68}$ En el sentido de que los terrenos eran asignados por sorteo, v. sortito (adv.), HeumanN, Hermann-SECKEL, Emil, cit. (n. 10), p. 548; v. sortio, ire (sv. sortitus, a, um), LEWIS, Charlton T.-SHORT, Charles, cit. (n. 10), p. 1733; v. sortitio, -onis [sortior] f., SEGURA, Santiago, cit. (n. 10), p. 722. 
Primero, aun cuando el pasaje de Dionisio se refiere a que la estimación de los gastos era conocida por los "árbitros", no se puede seguir a Serrao ${ }^{69}$, que insinúa que ella podría haberse realizado a través de los procedimientos de las legis actiones. Siguiendo a Nicosia ${ }^{70}$, por una parte, no hay claridad siquiera de la función jurisdiccional del pretor para la época de las XII Tablas ${ }^{71}$. Por la otra, no se debe olvidar que cuando los escritores romanos reproducen un texto literal de una norma o se refieren a su contenido, buscan proporcionar una interpretación ajustada a su tiempo, pero en ocasiones parten de supuestos errados, ya que el relato lo hacen desde una fase más evolucionada en el tiempo. No es éste el procedimiento de la apuesta sacramental, ni algún otro de la ley decenviral.

Luego, todavía menos, sería posible trasladar a la época altorepublicana, para

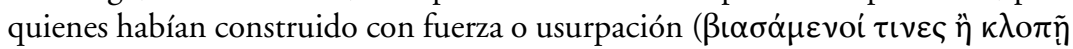
$\lambda \alpha \beta o ́ v \tau \varepsilon \varsigma)$, la clasificación clásica de poseedores de buena y mala fe que hacen Schwegler, Niebuhr e incluso, con algún matiz Serrao, puesto que igualmente les considera poseedores de mala fe.

Finalmente tampoco, en cierto punto con Merlin, que si bien tiene razón en que la lex concedió el pago de los gastos de construcción sin necesidad de distinguir

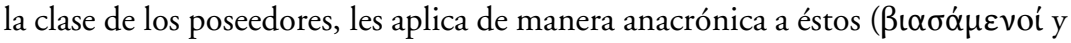

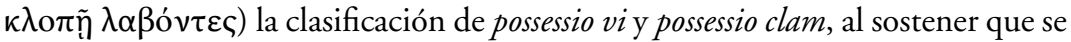
tratarían de categorías "parfaitement exactes au point de vue juridique"72. Pero es sabido que no hay certeza que a la fecha de la Lex Icilia de Aventino publicando, las categorías interdictales hayan sido aplicables al ager publicus; y menos aún, que se puedan trasladar a los agri privati. Es difícil plantear la existencia de una herramienta de este tipo como medio de pacificación social, cuando la organización social gentilicia, no propiamente estatal, carecía de la fuerza suficiente para ello.

Lo único que es posible admitir, es que se trata de terrenos que fueron cons-

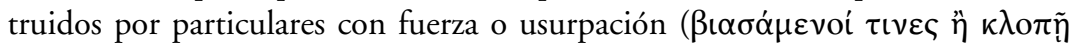
$\lambda \alpha \beta o ́ v \tau \varepsilon \varsigma)$, por lo tanto, sin la autorización estatal necesaria para edificar en suelo

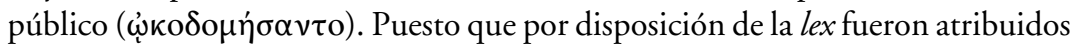
al pueblo, también por ello, sus nuevos asignatarios -para recibir los terrenos-

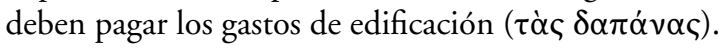

69 Respecto de los árbitros y la estimación de los gastos, Serrao siguiendo a Kaser, aun con la escasa información que ofrece el pasaje de Dionisio (puesto que nada dice de cómo debían ser elegidos y cómo funcionaban), no ve en ello una anticipación de épocas posteriores, puesto que los árbitros y el procedimiento arbitral se trataba ya en la Ley de las XII Tablas. Acepta que ellos podrían haber sido designados por los tribunos o por la asamblea de la plebe; o elegidos por acuerdo del asignatario y el viejo poseedor, aunque ninguna de las posibilidades sea demostrable, Serrao, Feliciano, Lotte per la terra e per la casa a Roma dal 485 al 441 a. C., cit. (n. 24), I, pp. 143-144.

${ }^{70}$ Vid. Nicosia, Giovanni, Il processo privato romano. La regolamentazione decemvirale (Catania, G. Giappichelli Editore, 1984), II, pp. 9-12.

${ }^{71}$ En este mismo sentido, FuenteseCA, Margarita, en La función procesal de los praedes litis et vindiciarum, RIDA, 53 (2006), p. 245.

${ }^{72}$ Merlin, Alfred, cit. (n. 47), pp. 75 n. 1. 
Así las cosas, como antes han planteado Merlin $^{73}$ y $\operatorname{Serrao}^{74}$, si bien la lex ofrece una cierta regulación a las tierras del monte del Aventino, se debe aceptar que lo hace en base a criterios de mera oportunidad política antes que jurídicos. Es ésta la justificación para otorgar el reembolso de los gastos de edificación en terrenos del ager publicus, que en nada atiende a la calidad del edificador. No se trata de la regulación incipiente de un régimen de reembolso gastos, y por ello, está lejos de ser un antecedente de la doctrina clásica de las impensae. Cualquier otra interpretación que se haga del pasaje de Dionisio, sería una anticipación histórica del lector.

\section{CONCLUSiÓN}

Parece acertado concluir, que un régimen propio de reembolso de impensas necesarias, útiles y voluptuarias, como el de las fuentes clásicas a propósito de la dote y, como extienden algunos romanistas a la reivindicatio, no encuentra regulación en la legislación arcaica sobre repartición, distribución o delimitación de las tierras en general.

Cuando se usan en las fuentes los términos impensae (impendere), sus derivados o cualquiera de los sinónimos (expendere, sumptus), se refiere al hecho mismo de "gastar" o realizar un "gasto", no - por tanto- al de "gasto reembolsable".

Con todo, no es conveniente desatender la Lex Icilia de Aventino publicando, puesto que efectivamente se autoriza en ella el pago de los gastos hechos por la edificación en terrenos adquiridos inicialmente por la fuerza y repartidos luego al pueblo.

Desde luego, parece haber aquí una proximidad temática y debe ser tenida en cuenta en su contexto, pero está claramente desconectada del sistema procesal, de manera que no se trata del procedimiento sacramental o de petición de árbitro -en realidad de ninguno de la ley decenviral-, pero tampoco pareciera ser el procedimiento interdictal.

Por lo dicho, no podrían aplicarse a la repartición de tierras del monte Aventino las categorías de la possessio vi y possessio clam, o la clásica de poseedores de buena o mala fe, a quienes se vieron en la necesidad de restituir estos terrenos.

Se agrega a lo anterior, que es poco probable encontrar para esta época el uso de cualquier término griego o latino que haya tenido el significado que persigue esta investigación, menos aún, cualquier alusión a alguna clasificación de las impensae.

Se trata, como se dijo, de una regulación dirigida con criterios políticos y el reembolso de cualquier tipo de "gastos" no es más que una consecuencia de ello. El asunto en esta materia no deja de ser oscuro y resulta difícil indagar más allá de lo que aquí se ha presentado.

${ }^{73}$ MerLin, Alfred, cit. (n. 47), pp. 77-78.

${ }^{74}$ SerRaO, Feliciano, Lotte per la terra e per la casa a Roma dal 485 al 441 a. C., cit. (n. 24), I, p. 142. 


\section{BiBLIOGRAFÍA}

Alföldi, Géza, Römische Sozialgeschichte (3a edición, Wiesbaden, Franz Steiner Verlag $\mathrm{GmbH}, 1984)$.

AmunÁtegui, Carlos, El origen de los poderes del "paterfamilias". I. El "paterfamilias" y la "patria potestas", en REHJ, 28 (2006), pp. 37-143.

—Las "gentes" y la propiedad colectiva, en REHJ, 32 (2010), pp. 39-58.

- The Collective Ownership and Heredium, en RIDA, 57 (2010), pp. 53-74.

- Las relaciones entre el mercado y la propiedad en el Lacio primitivo, en REHJ, 36 (2014), pp. 37-73.

BeHrends, Okko, La mancipatio nelle XII Tavole, en IURA, 33 (1982), pp. 46-103.

Berger, Adolf, Encyclopedic Dictionary of Roman Law (1953, reimp. Philadelphia, American Philosophical Society, 1991).

Binder, Julius, Die Plebs. Studien zur römischen Rechtsgeschichte (Leipzig, A. Deichert'sche Verlagsbuchhandlung Nachf, 1909).

Biondi, Biondo, Istituzioni di Diritto Romano (4ª edición, Milano, Dott. A. Giuffrè Editore, 1972).

BlánQueZ, Agustín, Diccionario Latín-Español (Barcelona, Editorial Ramón Sopena, 1985).

Bonfante, Pietro, Corso di Diritto Romano (Milano, Dott. A. Giuffrè Editore, 19631966).

Calonghi, Ferruccio, Dizionario latino italiano ( $3^{\text {a }}$ edición, Torino, Rosenberg \& Selier, 1990).

Cannata, Carlo Augusto, Enciclopedia del Diritto (Milano, Dott. A. Giuffrè Editore, 1958), XIV.

Capanelli, Daniele, Appunti sulla Rogatio Agraria di Spurio Cassio, en Legge e società nella repubblica romana (Napoli, Jovenne Editore, 1981), I.

CAPogrossi-Colognesi, Luigi, La terra in Roma antica: forme di proprietà e rapporti produttivi (Roma, La Sapienza Editrice, 1981).

-Cittadini e territorio. Consolidamento e trasformazione della 'civitas Romana' (Roma, La Sapienza Editrice, 2000).

—Diritto e potere nella storia di Roma (Napoli, Dott. Eugenio Jovene, 2007).

Castiglioni, Luigi-Mariotti, Scevola, IL. Vocabolario della Lingua Latina (3 $3^{\text {a }}$ edición, Torino, Loescher Editore, 1996).

Cervenca, Giuliano, Novissimo Digesto Italiano (Torino, Unione Tipografico-Editrice Torinese, 1970), XVII.

Costa, Emilio, Storia del diritto romano privato (Milano, Fratelli Bocca, 1911).

De Martino, Francesco, Storia della costituzione romana (Napoli, Dott. Eugenio Jovene, 1972), I.

- Storia económica di Roma antica (Firenze, La nuova Italia, 1979), I.

De Sanctis, Gaetano, Storia dei Romani (1907, reimp. Firenze, La Nuova Italia Editrice, 1960).

—Sul 'foedus Cassianum', en El Mismo, Scr. Minori (1929, reimp. Roma, Edizioni di Storia e Letteratura, 1976), IV.

DiósDi, György, Ownership in Ancient and Preclassical Roman Law (Budapest, Akadémiai Kiadó, 1970).

D'IPpOLITO, Federico, In recent years credulity has taken over again, en Labeo, 21 (1975), pp. 197-210. 
D'Ors, Alvaro, Derecho Privado Romano (3 ${ }^{\text {a }}$ edición, Pamplona, Ediciones Universidad de Navarra S. A., 1977).

DREYFus, Robert, Essai sur les lois agraires sous la république romaine (1898, reimp. Roma, L'Erma di Bretschneider, 1971).

ELSTER, Marianne, Studien zur Gesetzgebung der frühen römischen Republik-Gesetzesanhäufungen und-wiederholungen (Bern, Peter Lang Frankfurt/M., 1976).

ERnout, Alfred-Meillet, Antoine, Dictionaire etymologique de la langue latine (4a edición, Paris, Klincksiek, 2001).

FAYER, Carla, La familia romana, II: Sponsalia, matrimonio, dote (Roma, L'Erma di Bretschneider, 2005).

Forcellini, Egidio, Lexicon Totius Latinitatis (1864, reimp. Patavii, Gregoriana, Arnaldus Forni Excudebat Bononiae, 1965).

Franciosi, Genaro, La plebe senza genti e il problema della rogatio Canuleia, en EL Mismo (editor), Richerche sulla organizzazione gentilizia romana (Napoli, Dott. Eugenio Jovene, 1984), I.

Franciosi, Genaro, Leges Regiae (Napoli, Dott. Eugenio Jovene, 2003).

FuENTESECA, Margarita, La formación romana del concepto de propiedad (Madrid, Dykinson, 2004).

—La función procesal de los praedes litis et vindiciarum, en RIDA, 53 (2006), pp. 237-264.

GABA, Emilio, Roma Arcaica. Storia e Storiografia (1964, reimp. Roma, Edizioni di Storia e Letteratura, 2000).

GiRARD, Paul-Frédéric, Manuel élémentaire de droit romain ( $8^{\mathrm{a}}$ edición, Éditions Dalloz, Paris, 2003).

Glare, P. G. W., Oxford Latin Dictionary (1982, reimp. Oxford, Oxford University Press, 2009), I.

GonzÁlez-Palenzuela, María Teresa, Impensas útiles dotales y voluntas mulieris, en Anuario de la Facultad de Derecho, 11 (1993), pp. 399-414.

- Las impensas en el Derecho Romano Clásico (Extremadura, Universidad de Extremadura, 1998).

Gutiérrez-Alviz y Armario, Faustino, Diccionario de Derecho Romano (4ª edición, Madrid, Editorial Reus S. A., 1995).

Heumann, Hermann-SeCKel, Emil, Handlexikon zu den Quellen des römischen Recht (1907, reimp. Graz, Akademische Druck- u. Verlagsanstalt, 1971).

IHnE, Wilhelm, Römische Geschichte (Leipzig, Verlag von Wilhelm Engelmann, 1868), I.

IHERING, Rudolf, Geist des römischen Rechts auf den verschiedenen Stufen seiner Entwicklung (2a edición, Leipzig, Druck und Verlag von Breitkopf und Härtel, 1866), I.

Karlowa, Otto, Römische Rechtsgeschichte (Leipzig, Verlag von Veit \& Comp., 1901).

LANGE, Ludwig, Römische Alterthümer ( $3^{\text {a }}$ edición, Berlin, Weidmannsche Buchhandlung, 1876), I.

LATORRE, Ángel, Voluntas mulieris y reembolso de las impensas útiles dotales, en IURA, 5 (1954), pp. 209-212.

LÉvY, Jean-Philippe, Les impenses dotales en droit romain classique (Paris, Librarie du Recueil Sirey, 1937).

Lewis, Charlton T.-Short, Charles, A Latin Dictionary (1879, reimp. Oxford, Clarendon Press, 1988).

Macé, Antonin, Des lois agraires chez les romains (Paris, Joubert, 1846). 
Maschke, Richard, Zur Theorie und Geschichte der Römischen Agrargesetze (1906, reimp. Napoli, Dott. Eugenio Jovene, 1980).

Merlin, Alfred, L'Aventin dans l'antiquité (Paris, Albert Fontemoing, 1906).

Meyer, Eduard, Der Ursprung des Tribunats und die Gemeinde der Vier Tribus, en Hermes, 30 (1895), pp. 1-24.

Momigliano, Arnaldo, The Rise of the Plebs in the Archaic Age of Rome, en Raaflaub, Kurt (editor), Social Struggles in Archaic Rome: New Perspectives on the Conflict of the Orders (2a edición, Malden, MA, Blackwell Publishing, 2005), pp. 168-184.

Mommsen, Theodor, Römische Geschichte ( $5^{a}$ edición, Berlin, Wiedmannsche Buchhandlung, 1869), III.

—Römisches Staatsrecht (3a edición, Leipzig, Hirzel, 1887), III.

Natelson, Robert, Comments on the Historiography of Condominium: The Myth of Roman Origin, en Oklahoma City University Law Review, 12 (1987), I.

Nicosia, Giovanni, Il processo privato romano. La regolamentazione decemvirale (Catania, G. Giappichelli Editore, 1984), II.

Niebuhr, Barthold Georg, Römische Geschichte (Berlin, Verlag von G. Reiner, 18331836).

NiederläNDER, Hubert, Zur Herkunft der römischen Impensen-Dreiteilung, en ZSS. r.A., 75 (1958), pp. 201-219.

NIESE, Benedictus, Das sogenannte Licinisch-Sextische Ackergesetz, en Hermes, 23 (1888), pp. 410-423.

Oliviero, Giuseppina, La 'lex Icilia de Aventino publicando', en Index, 25 (1997), pp. 221-235.

PAIS, Ettore, Storia di Roma (Torino, Carlo Clausen, 1898), I.

Pastori, Franco, Prospettiva storica del diritto di superficies, en St. in memoria di Guido Donatuti (Milano, Cisalpino-La Goliardica, 1973), II.

PARETI, Luigi: Storia di Roma e del mondo romano (Torino, Unione Tipografico-Editrice Torinese, 1952), I.

Pérez, María del Pilar, El reembolso de los gastos dotales según la nueva regulación justinianea, en D’Ippolito, Federico (coordinador), Фı $\lambda i ́ \alpha$. Scr. per Gennaro Franciosi (Napoli, Satura Editrice, 2009), III, pp. 2029-2062.

Pernice, Alfred, Parerga, 2, Beziehungen des offentlichen romischen Rechts zum Privatrecht, ZSS. r.A., 5 (1884), pp. 1-135.

ResZCZY SKI, Jaroslaw, Impendere, Impensa, Impendium, en SDHI, 55 (1989), pp. 191-252.

RICCA-BARBERIS, Mario, Le spese sulle cose immobili e il loro risarcimento (Torino, Unione Tipografico-Editrice Torinese, 1914).

Riccobono, Salvatore, Gli Scholii Sinaitici, en BIDR, 9 (1896), pp. 217-300.

-Distinzione delle impensae e la regola fructus intelliguntur deductis impensis, en $A G$, 58 (1897), pp. 60-92.

- Tracce di diritto romano classico nelle collezioni guiridiche bizantine, en BIDR, 18 (1906), pp. 197-222.

-Il compenso per spese fatte da possessori su cose altrui, en BIDR, 47 (1940), pp. 1-30.

-Dal Diritto romano classico al diritto moderno. A proposito di D. 10, 3, 14 [Paul. 3 ad Plautium], en El Mismo, Scr. di diritto romano (1917, reimp. Palermo, Università degli Studi, 1964), II.

Richards, Jean-Claude, Les origines de la plèbe romaine. Essai sur la formation du dualisme patricio-plébéeien (Roma, École française, 1978). 
Roselaar, Saskia, Public Land in the Roman Republic (Oxford, Oxford University Press, 2010).

Rotondi, Giovanni, Leges publicae populi romani (1912, reimp. Hildesheim-ZürichNew York, Georg Olms Verlag, 1990).

Salazar Revuelta, María, Evolución histórico-juridica del condominio en el Derecho romano (Jaén, Universidad de Jaén, 2003).

Schulz, Fritz, Impensae necessariae dotem ipso iure minuunt, en ZSS. r.A., 34 (1913), pp. 57-106.

SCHWEgler, Albert, Römische Geschichte im zeitalter des Kampfs der Stände (2ª edición, Tübingen, Verlag der H. Laupp'schen Buchhandlung, 1870), II.

Segura, Santiago, Nuevo diccionario etimológico Latín-Español y de las voces derivadas (Bilbao, Universidad de Deusto, 2003).

SERRAO, Feliciano, Lotte per la terra e per la casa a Roma dal 485 al 441 a. C., en EL Mismo (editor), Legge e società nella repubblica romana (Napoli, Jovenne Editore, 1981), I, pp. 51-196.

-Diritto privato economia e società nella storia di Roma (Napoli, Dott. Eugenio Jovene, 2008), I.

Treggiari, Susan, Roman Marriage: "Iusti Coniuges" from the Time of Cicero to the Time of Ulpian (Oxford, Clarendon Press, 1991).

Van Der Merwe, Cornelius, European Condominium Law (Cambridge, Cambridge University Press, 2015).

Voci, Pasquale, Istituzioni di Diritto Romano (6 edición, Milano, Dott. A. Giuffrè Editore, 2004).

\section{FUENTES}

BASILICORUM LIBRI LX... a Gustavo Ernesto Heimbachio aliisque collatorum integriores cum scholiis edidit... translationem latinam et adnotationem criticam adiecit D. Carolus Guilelmus Ernestus Heimbach antecesor Jenensis (Lipsiae, Sumptibus Joh. Ambrosii Barth., 1843), III.

Denys D'Halicarnasse, Les antiquites romaines de Denys d'Halicarnasse (Mouchard, François-Camús, Alfredo-Lottin, Philippe-Nicolas (traductores), París, chez Philippe-Nicolas Lottin, 1723).

Dionisio de Halicarnaso, Historia Antigua de Roma (Jiménez, Elvira-Sánchez, Ester (traductores), Madrid, Editorial Gredos, 1998).

FIRA (Florentiae, apud S. A. G. Barbèra, 1968).

Goold, G. P., The Loeb Classical Library, The Attic Nights of Aulus Gellius (1927, reimp. Rolfe, John C. (traductor), Harvard University Press, Cambridge-MassachusettsLondon, 1993).

Guarneri Citati, Andrea, Nuovo Digesto Italiano (Torino, Unione Tipografico-Editrice Torinese, 1940), XII.

Halm, Karl, Valeri Maximi Factorvm et dictorvm memorabilivm: libri Novem (Lipsiae, In aedibvs Tevbnerianis, 1865).

Henderson, Jeffrey, The Loeb Classical Library. The Roman Antiquities (1947, reimp. Cary, Earnest (traductor), Cambridge-Massachusetts-London, Harvard University Press, 2002).

KeMPF, Karl, Valeri Maximi Factorum et dictorum memorabilium libri novem (Berolini, Impensis Georgii Reimeri, 1854), p. 620. 
Lenel, Otto, Palingenesia Iuris Civilis (1889, reimp. Roma, Il Cigno Galileo Galilei, 2000), I, col. 1156 (n. 1127).

NisARD, Désiré, Collection des Auteurs Latins, Oeuvres de Tite-Live (París, Chez Firmin Didot Fréres, 1864), I. 
